\title{
Global Relationship between Fronts and Warm Conveyor Belts and the Impact on Extreme Precipitation*
}

\author{
JENNIFER L. CATTO \\ School of Earth, Atmosphere and Environment, Monash University, Melbourne, Victoria, Australia \\ ERICA MADONNA AND HANNA JOOS \\ Institute for Atmospheric and Climate Science, ETH Zurich, Zurich, Switzerland \\ IRINA RUDEVA AND IAN SIMMONDS \\ School of Earth Sciences, University of Melbourne, Melbourne, Victoria, Australia
}

(Manuscript received 3 March 2015, in final form 16 July 2015)

\begin{abstract}
Extratropical cyclones are responsible for many extreme precipitation events in the midlatitudes. Warm conveyor belts (WCBs) and fronts are known to be related to the uplift and hence the precipitation within cyclones. The authors have investigated the link between WCBs and fronts and how such a link impacts the occurrence of extreme precipitation events. WCB trajectories have been calculated from the ERA-Interim dataset, and low-level (below $790 \mathrm{hPa}$ ) and midlevel (790-600 hPa) WCBs have been considered. These have been matched with objectively identified fronts (i.e., characterized by an overlap of WCB and front somewhere along the front). About $10 \%$ of cold fronts, $8 \%$ of warm fronts (identified using a thermal criterion), and $15 \%$ of wind fronts (identified using a wind shift method) are matched with WCBs, while up to $70 \%$ of WCBs are matched with fronts. Some WCBs, especially in the Southern Hemisphere, are not matched with either type of front (up to $70 \%$ east of Australia). The relationship between WCBs and fronts does not change much between the low levels and midlevels, indicating that the WCBs are already strongly associated with fronts during the lowest part of their ascent, although in the Southern Hemisphere the WCBs are more often related to warm fronts during their midtropospheric ascent. In parts of the midlatitudes, more than $60 \%$ of extreme precipitation events match either cold or warm fronts, and up to $90 \%$ of these have matched WCBs. Fronts associated with WCBs are found to be between 2 and 10 times more likely to produce extreme precipitation events than fronts without associated WCBs.
\end{abstract}

\section{Introduction}

Extratropical cyclones are intimately linked with the day-to-day variability of weather in the midlatitudes. One important aspect of this variability is the associated precipitation. Ascending air in these systems induces precipitation that can, at times, be very heavy and cause

\footnotetext{
* Supplemental information related to this paper is available at the Journals Online website: http://dx.doi.org/10.1175/JCLI-D-150171.s1.

Corresponding author address: Jennifer L. Catto, School of Earth, Atmosphere and Environment, Monash University, Melbourne VIC 3800, Australia.

E-mail: jennifer.catto@monash.edu
}

major flooding and damage (e.g., Pitt 2008). Recently, a number of studies have shown the climatological importance of cyclones and their associated features (e.g., fronts and warm conveyor belts) for both the total precipitation and extreme precipitation in the midlatitudes (Pfahl and Wernli 2012; Hawcroft et al. 2012; Catto and Pfahl 2013; Papritz et al. 2014; Pfahl et al. 2014).

The structure and development of extratropical cyclones have been studied for a long time, with a wellknown conceptual model (the Norwegian model) being developed early in the twentieth century using case studies (Bjerknes and Solberg 1922). This model described extratropical cyclones in terms of the battling of the warm and cold air masses at the polar front. The resultant warm and cold fronts are associated with uplift and hence precipitation. The airflows within cyclones 
were later identified, and Browning (1971) and Harrold (1973) were the first to describe the warm conveyor belt (WCB) model. Originally WCBs were identified using isentropic flow analysis and interpretation of satellite images (e.g., Green et al. 1966; Bader et al. 1995). In the 1980s, Browning (1986) gave an overview of conceptual models of precipitation systems. He identified in satellite images different types of WCBs: those with rearward- and forward-sloping ascent. Although the main motion of the warm and moist air is parallel to the cold front, there is a small ageostrophic component perpendicular to the front that produces the two contrasting ascents. The slantwise ascent in rearward-sloping WCBs occurs in the vicinity of and above the cold frontal zone and is related to the anabatic cold frontal situation, where the surface cold front is sharp and produces both a narrow region of very heavy precipitation at the surface front and a larger region of much lighter precipitation behind the front. Differently, the forward-sloping WCB corresponds to the katabatic cold front situation, where the ascent takes place ahead of the cold front and the flow turns anticyclonically, overtaking the warm front and producing a wide region of moderate-to-heavy precipitation (Browning 1986).

Since then, Lagrangian trajectory analysis (e.g., Wernli and Davies 1997; Wernli 1997; Eckhardt et al. 2004; Madonna et al. 2014) has been used in more objective ways to identify WCBs. These studies showed that the trajectories with maximum ascent, and therefore defined as WCB trajectories, actually undergo cross-isentropic flow and are strongly associated with diabatic processes. Wernli (1997) found that there are different distinct airflows within cyclones that would meet the criteria of WCBs used in this study. One of these flows begins in the warm sector and undergoes rearward-sloping ascent above the cold front (as in the rearward-sloping WCB in the anabatic front configuration), and another rises from the warm sector over the warm front (as in the forward-sloping katabatic front). These two features were also identified in moist idealized baroclinic wave simulations by Schemm et al. (2013). We therefore expect that WCBs will be associated with both cold and warm fronts. Strong ascent may also be forced without the presence of sharp frontal zones (e.g., in cutoff lows). In this case the troposphere below the upper-level potential vorticity anomaly is unstable (Nieto et al. 2005), and the upper-level forcing induces ascent through potential vorticity advection (e.g., Carroll 2003). Clearly, fronts and WCBs are strongly related, but, as yet, the climatological link between WCBs and fronts has not been established.

Madonna et al. (2014) derived a climatology of WCBs based on the European Centre for Medium-Range Weather Forecasts (ECMWF) interim reanalysis (ERA-Interim) dataset (Dee et al. 2011) using Lagrangian trajectory analysis. This climatology identified WCBs as bundles of trajectories undergoing significant ascent (over $600 \mathrm{hPa}$ in 2 days) in the vicinity of an extratropical cyclone. The preferred regions for WCB initialization were found to be in the major oceanic storm-track regions of the Northern and Southern Hemispheres. As is the case with the climatology of extratropical cyclones, there is a strong seasonal cycle in the frequency of WCBs, with the maximum in the winter season. Pfahl et al. (2014) linked WCBs with surface estimates of precipitation to quantify the importance of WCBs for precipitation. They found that in the midlatitudes, about $40 \%$ of the precipitation is associated with WCBs and that in some regions up to $80 \%$ of the extreme precipitation events are associated with WCBs.

Berry et al. (2011) and Simmonds et al. (2012) produced frontal climatologies using a thermal method and a wind shift method, respectively. Catto et al. (2012) showed, using the front identification method of Berry et al. (2011), that in the midlatitudes up to $90 \%$ of all precipitation is associated with fronts, and Catto and Pfahl (2013) further found that in some places over $90 \%$ of the extreme precipitation events are associated with fronts. Papritz et al. (2014) also found a strong link between fronts and heavy precipitation events for fronts identified using the method of Simmonds et al. (2012), with up to $70 \%$ of heavy precipitation associated with fronts over parts of the Southern Ocean (with another 10\%-20\% associated with cyclones).

Catto and Pfahl (2013) also found that in the midlatitude regions, where fronts are very frequently identified, only about $5 \%$ of the identified fronts produced precipitation extremes. Frontogenesis occurs when the ageostrophic circulation with ascent on the warm side and descent on the cold side acts to tighten the temperature gradient across the front (e.g., Keyser et al. 1988). It is at this time that the heaviest rainfall should be expected. Rudeva and Gulev (2011) showed that the heaviest rainfall in a composite cyclone is seen during the development stage, when the fronts are undergoing strengthening of the temperature gradient. Later in the cyclone life cycle, when the fronts are still present but not developing as strongly (or undergoing frontolysis), the precipitation volume decreases. The key role that WCBs play in the development of extratropical cyclones (e.g., Schemm and Wernli 2014) suggests that fronts that are dynamically active (undergoing frontogenesis) are more likely to have associated WCBs and precipitation extremes. To achieve the ascent criterion for a WCB, the trajectories must be in a baroclinic environment and contain a large amount of moisture. When this moisture is lifted, it condenses to produce rainfall. Fronts that are 
linked to WCBs will therefore be associated not only with strong ascent but also with large amounts of moisture. According to Browning (1990), WCBs are the most precipitation-forming airstreams in extratropical cyclones. They are strong cross-isentropic flows that, on average, experience potential temperature changes of more than $20 \mathrm{~K}$ (Madonna et al. 2014). This is related to the release of latent heat during condensation and precipitation formation. Thus, if WCBs are connected to fronts, we expect large amounts of precipitation.

Both WCBs and fronts are important features of extratropical cyclones and are clearly important for generating the precipitation associated with these systems. In this paper we bring together the WCB identification of Madonna et al. (2014) and the front identification methods of Berry et al. (2011) and Simmonds et al. (2012) to answer the following questions.

1) How often are WCBs associated with fronts, and fronts associated with WCBs, and what is the distribution between cold and warm fronts?

2) Do the WCBs preferentially relate to different types of fronts at different stages in the WCB life cycles?

3) If fronts are linked to WCBs, are they more likely to produce extreme precipitation events than fronts that are not linked to WCBs?

Section 2 describes the data used in this study and gives a brief description of the various objective feature identification methodologies and how they are linked together. The link between WCBs and fronts is quantified globally in section 3, while the relationship to extreme precipitation is given in section 4 . These results are discussed and a summary is given in section 5 .

\section{Method and tools}

\section{a. Data}

We use ERA-Interim (Dee et al. 2011) from 1979 to 2010 for the analysis in this study. The fronts are calculated using data obtained at $1.5^{\circ}$ resolution and then the output is gridded at $2.5^{\circ}$ resolution. The WCBs are calculated with data interpolated to a grid with $1^{\circ}$ horizontal resolution. Estimates of 6-hourly accumulations of precipitation are obtained on a $1.5^{\circ}$ grid. Then the WCB and precipitation data are all interpolated to a $2.5^{\circ}$ grid so that they have the same resolution as the fronts. Descriptions of how the data are used to find the WCBs and fronts are given in the following sections.

\section{b. WCB trajectories and objects}

The WCB identification method is described in detail in Madonna et al. (2014). Trajectories are calculated from ERA-Interim using the Lagrangian analysis tool (LAGRANTO; Wernli and Davies 1997). The trajectories are identified as WCBs if they meet certain criteria: they must ascend more than $600 \mathrm{hPa}$ from below $790 \mathrm{hPa}$ within 2 days, and they must occur in the vicinity of an extratropical cyclone [i.e., pass through the region enclosed by the outermost closed sea level pressure contour of the cyclones identified using the method of Wernli and Schwierz (2006)].

To investigate the relationship between WCBs and fronts, we transform the WCB trajectories into twodimensional WCB "objects" from the lower (below $790 \mathrm{hPa}$ ) and middle (between 790 and $600 \mathrm{hPa}$ ) troposphere. The adopted procedure for generating the lowlevel 2D WCB objects is shown in Fig. 1. At a given time $t$, all WCB trajectories that are located in this layer are considered. This includes trajectories that start at time $t$, or at any previous analysis time, as long as they are located in the specified layer. The dark blue trajectory in Fig. 1a, which starts $18 \mathrm{~h}$ before and is above the boundary layer at time $t$, is not considered for the lowlevel 2D WCB object.

Once the appropriate trajectories are selected, the horizontal positions of the trajectories at time $t$ are gridded on a $2.5^{\circ} \times 2.5^{\circ}$ grid (Fig. 1b). A smoothing radius of $250 \mathrm{~km}$ is applied to the WCB trajectories in order to obtain a continuous area that encloses all WCB positions by adding up the contributions from the individual trajectories. The final WCB object is enclosed by the red contour in Fig. 1b. If the objects are smaller than 10 grid points-which approximately means that they have fewer than 30 trajectories-they are not considered. Using the smoothing radius gives the WCBs a finite area of influence.

The transformation of WCB trajectories to objects will artificially enhance the frequency of WCBs compared to the climatology of Madonna et al. (2014). This is because in Madonna et al. (2014), the frequency of WCB trajectories represents the percentage of 6-hourly time steps during which at least one WCB trajectory is located somewhere in the vertical column represented at each grid point. In that case, only time $t=0$ for each trajectory is considered, whereas here the objects are computed using trajectories that are located at the given time below $790 \mathrm{hPa}$ independent of their starting time. This means that, for a given time $t$, the trajectories may have started at different times (see different colors in Fig. 1) and the same trajectory may be counted for more than only one time $t$.

To help answer one of the key questions of the paper of how the relationship between fronts and WCBs changes through the WCB lifetime, we also produced WCB objects based on trajectories found higher in the 


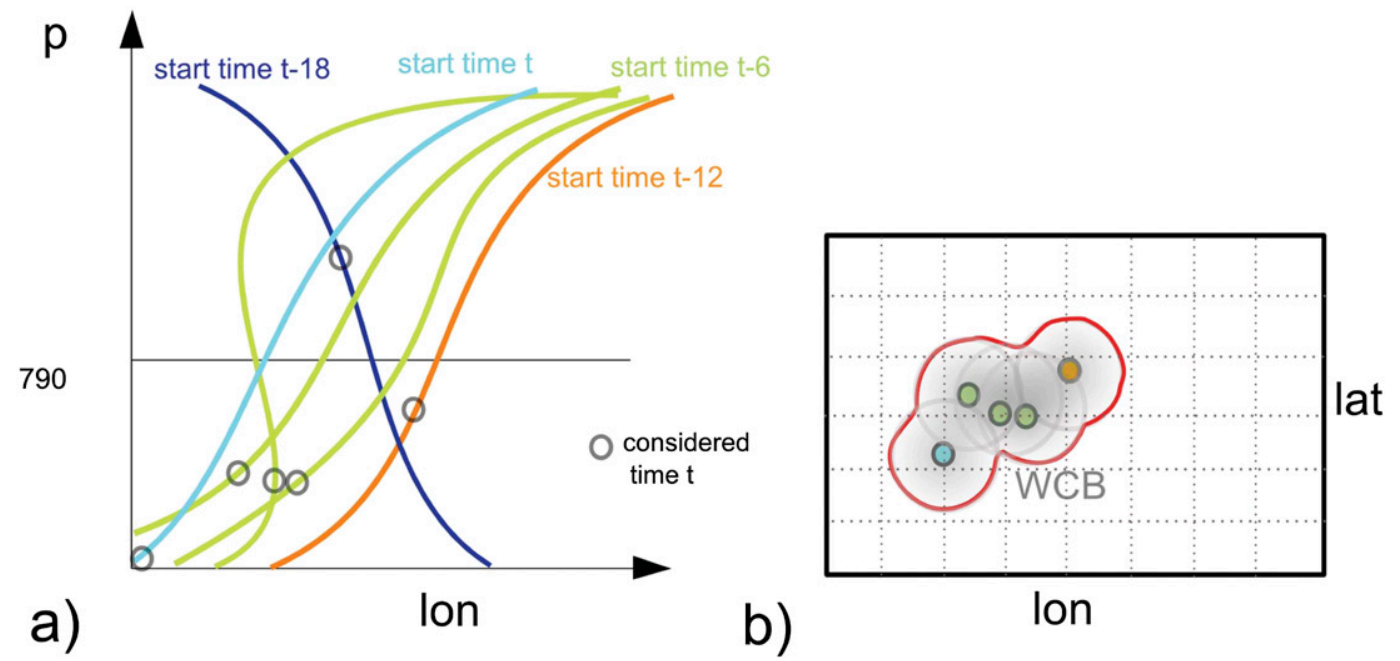

FIG. 1. Schematic illustration of the method used to obtain WCB objects from trajectories. (a) 48-h trajectories starting at four different times are shown (colored lines), including the position of the air parcels along the trajectories at time $t$ (gray circles). (b) Horizontal position of the trajectories shown in (a) at time $t$ that are located below $790 \mathrm{hPa}$ (color-filled gray circles) and the resulting WCB object at time $t$ (red contour).

atmosphere (which, by definition, are at a later point in their lifetime). For these objects, trajectory points found between 790 and $600 \mathrm{hPa}$ at time $t$ were used. These objects are referred to as midlevel WCB objects.

\section{c. Front identification}

We have used two different front identification methods to investigate the sensitivity of the link between fronts and WCBs to this identification. One method uses gradients in wet-bulb potential temperature (Berry et al. 2011), and the other identifies shifts in winds (Simmonds et al. 2012).

\section{1) WeT-BULB POTENTIAL TEMPERATURE METHOD}

Based on the techniques of Hewson (1998), Berry et al. (2011) developed an objective front identification method that could be applied to relatively lowresolution data from reanalysis products or climate models. The method has previously been used by Catto et al. (2012, 2013, 2014) and Catto and Pfahl (2013), and the brief description of the method given here parallels theirs. A thermal front parameter is calculated, defined by Renard and Clarke (1965) as the magnitude of the gradient of a thermodynamic scalar quantity, resolved into the direction of the gradient of that quantity, from the $850-\mathrm{hPa}$ wet-bulb potential temperature. A threshold of $-8 \times 10^{-12} \mathrm{~K} \mathrm{~m}^{-2}$ is used to mask the field (see Berry et al. 2011). From this the frontal points are identified as the points where the thermal front parameter is equal to zero, and these are linked into contiguous fronts. The frontal speed and direction is then used to separate the fronts into the cold, warm, and quasistationary fronts. In the present study we are considering only the cold and warm fronts. The fronts are interpolated to a $2.5^{\circ}$ grid.

\section{2) WIND SHIFT METHOD}

Simmonds et al. (2012) developed a method to identify frontal regions based on the change in the direction of the 10-m wind [from northwest to southwest in the Southern Hemisphere (SH) and from southwest to northwest in the Northern Hemisphere (NH)] and the change in the meridional component of the wind velocity, which must exceed $2 \mathrm{~m} \mathrm{~s}^{-1}$ in $6 \mathrm{~h}$. These criteria are evaluated at each grid point, using consecutive 6-hourly analysis times. They do not generally allow the identification of warm fronts, or fronts that are more zonally oriented. After identification of the frontal area, a series of frontal edge points is produced. These frontal edge points have been identified using ERAInterim data and have also been interpolated to a $2.5^{\circ}$ grid for consistency with the wet-bulb potential temperature method, and they are herein referred to as wind fronts.

The wind shift identification method picks up features that are more similar to cold fronts because of the preferred orientation. The two methods have been shown to perform in a similar manner when considering a small region over Western Australia (Hope et al. 2014). Schemm et al. (2015) also showed that fronts identified using the wind shift method, and those identified using a slightly different thermal method, found similar features, albeit with a slight shift in the exact locations. 


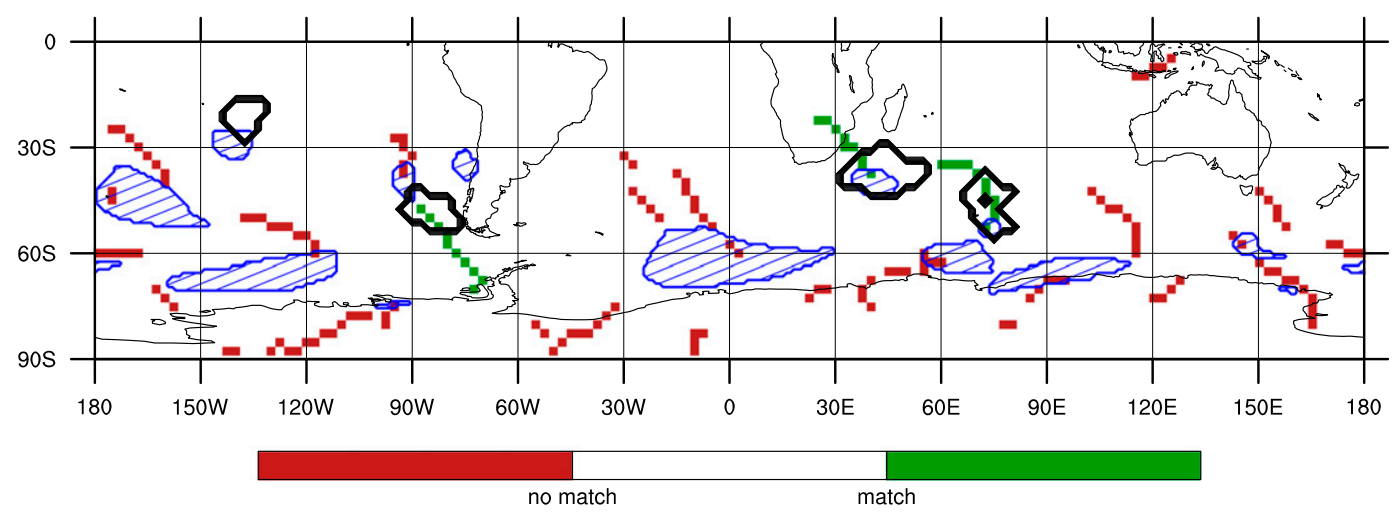

FIG. 2. Objects at 0000 UTC 9 June 2010. WCB objects are shown by the black contours, regions affected by cyclones are identified by the blue hatched areas, and cold fronts are identified using the thermal method shown in green and red. Where the front object overlaps with a WCB object, they are recorded as matching (and shown in green), and where the front object does not overlap, they are recorded as not matching (and shown in red).

\section{d. Matching procedure}

The matching between WCBs and fronts is performed based on a simple overlay of the objects. If a WCB object and a front object have any part of them overlapping, all grid points within the object are classed as matching. Figure 2 shows an example for the situation at 0000 UTC 9 June 2010. Cyclones are identified as the largest closed contour around a sea level pressure minimum in the ERA-Interim dataset (see Wernli and Schwierz 2006; Madonna et al. 2014) and are displayed with the blue contours. The WCB objects are displayed by black contours. The green and red lines show the fronts identified using the wet-bulb potential temperature method that match or do not match with WCBs, respectively.

To the southeast of South Africa, there is an example of a cyclone with an associated front and a WCB object overlaying it. Every grid point along this front will be classed as a front matching a WCB at this time, and every grid point within the WCB object will be classed as a WCB matching a front. In the South Atlantic Ocean, there is an example of a cyclone with associated front but no WCB at this time, whereas in the South Pacific Ocean at around $30^{\circ} \mathrm{S}$ there is a small cyclone with an associated WCB but no identified fronts.

The matching of the WCB and front objects on a gridbox basis yields two different quantities: the frequency of occurrence of matching (or nonmatching) objects and the proportion of matching (or nonmatching) objects. For example, the frequency of occurrence of WCBs matching cold fronts is given as a percentage of all times analyzed that a WCB matches a cold front. Then, the proportion of WCBs matching a cold front is the frequency of occurrence of the matching of the cold front normalized by the frequency of occurrence of WCBs (also given as a percentage). This is done at every grid point, so that when the WCB and cold front match, this characterizes every frontal grid point and every WCB object grid point belonging to the matched objects. If a WCB object overlaps with both a cold front and a warm front simultaneously, then it is counted in both categories as WCB matching cold front and WCB matching warm front. A third quantity is the proportion of matching or nonmatching objects found by counting the objects over the entire hemisphere.

\section{e. Linking to extreme precipitation events}

Precipitation data from ERA-Interim are used to investigate extreme precipitation events. The 99th percentile of the 6-hourly precipitation accumulation estimates are calculated at each grid point as in Pfahl and Wernli (2012) and Catto and Pfahl (2013) using all 6-hourly values (including zeros) within the relevant season, and the extreme precipitation events for each season are defined as the 6-hourly periods where accumulations exceed this threshold. Precipitation is a forecast variable in the ERA-Interim dataset and has been shown to represent quite accurately the timing of extreme precipitation events, although the actual amounts are lower when compared to the satellitederived Climate Prediction Center morphing method (CMORPH; Joyce et al. 2004) dataset (Pfahl and Wernli 2012). The method used to link the fronts (matched or not matched with WCBs) to the extreme precipitation events is the same as that used in Catto and Pfahl (2013), and the description parallels theirs. If there is an extreme precipitation event identified, a search is performed for a front in the grid box and the eight neighboring grid boxes at two times-at the start and at the end of the precipitation accumulation period. If a 


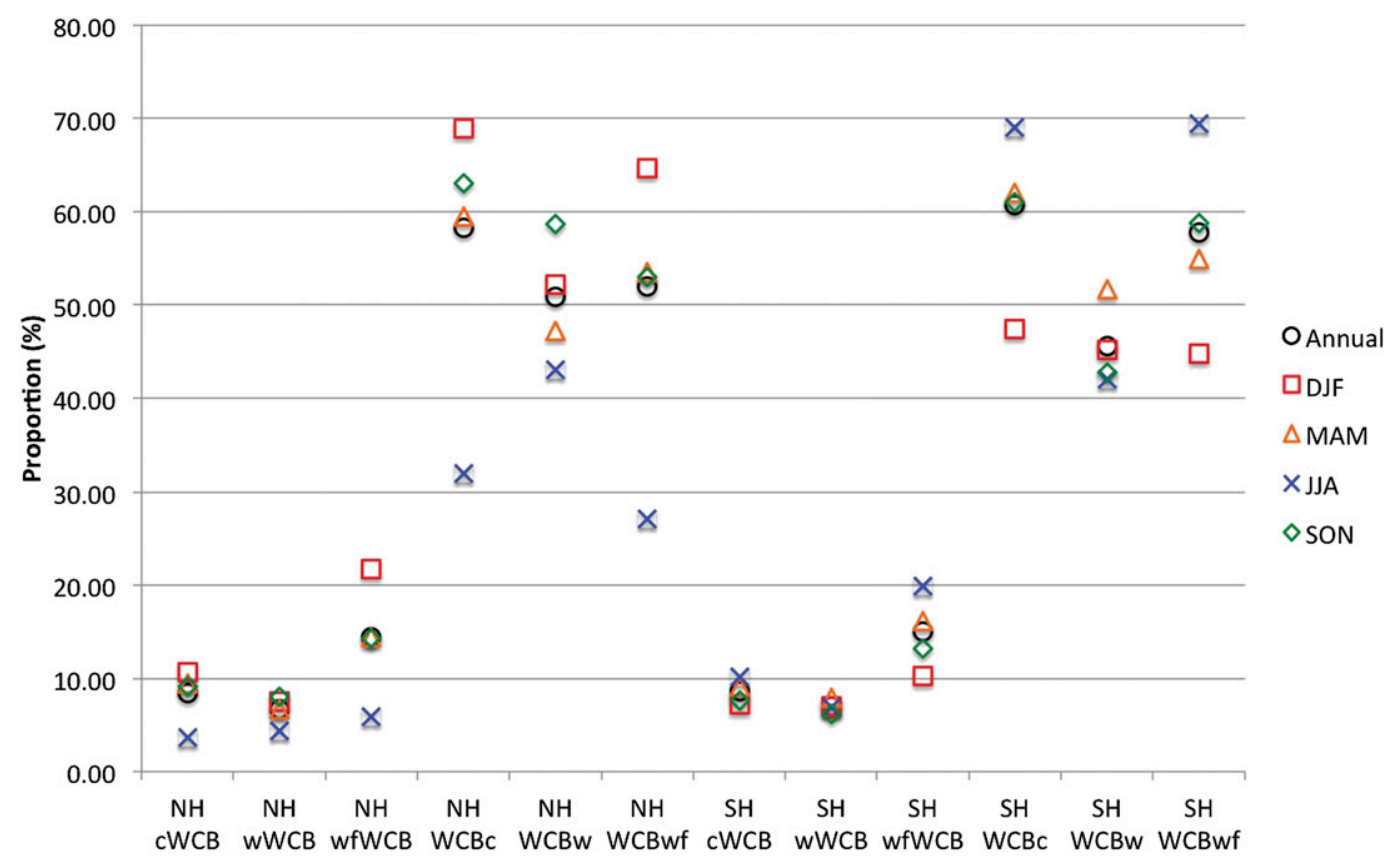

FIG. 3. Graph showing the summary statistics for the relationship between WCBs and fronts. Proportion of objects associated with other objects (cWCB, wWCB, WCBc, WCBw, wfWCB, and WCBwf).

front is present at either of these times, the extreme precipitation event is classed as matching with a front.

\section{Relationship between fronts and warm conveyor belts}

\section{a. Overview}

To give an overview of the relationship between fronts and WCBs, the proportion of each different type of object (WCB, cold front, warm front, and wind front) associated with each other object has been calculated, and a summary of these values (for each season as well as annually) is shown in Fig. 3. These values have been calculated by counting the objects identified at each analysis time.

The first thing to notice is that the proportion of fronts (of any type) associated with WCBs is much lower than the proportion of WCBs associated with fronts. This is due to the relatively high frequency of fronts compared to WCBs (an average frequency of 23 cold fronts, 25 warm fronts, 13 wind fronts, and 3 WCBs identified per analysis time in the NH). Also, since the WCBs must, by definition, be in the vicinity of a cyclone, any fronts not associated with a cyclone would not match up with a WCB. This does suggest that there may be ascending trajectories not included in the WCB climatology since they are not close to a cyclone that may be related to fronts. Since the present study is considering specifically the WCBs as defined in Madonna et al. (2014), these situations will not be considered here. The proportion of cold fronts and wind fronts associated with WCBs is highest in winter (when the WCBs are themselves more frequent; see Madonna et al. 2014).

There are considerably fewer wind fronts than cold fronts identified, so the percentage of wind fronts associated with WCBs (wfWCB) is higher than that of cold fronts (cWCB). The percentage of wind fronts associated with WCBs shows a strong seasonal cycle, although the seasonal cycle in the number of fronts identified is larger for cold fronts than for wind fronts (not shown).

In general the WCBs are slightly more strongly associated with cold fronts (WCBc) than warm fronts (WCBw), with this difference being larger in the $\mathrm{SH}$ than NH. This suggests that there are a large number of WCBs that are consistent with the rearward-sloping ascent in the anabatic cold front situation (Browning 1986). There is a strong seasonal cycle in $\mathrm{WCBc}$, with lower values (about $47 \%$ in the $\mathrm{SH}$ and $32 \%$ in the $\mathrm{NH}$ ) in summer and higher values (about $69 \%$ in both the $\mathrm{SH}$ and $\mathrm{NH}$ ) in winter.

The annual proportion of WCBs associated with the wind fronts (WCBwf) in the $\mathrm{NH}$ is about $6 \%$ lower than with the cold fronts (WCBc). This may be associated with the wind fronts not being identified as often, owing to the less meridional orientation of fronts in the $\mathrm{NH}$ or the wind fronts being shorter (Schemm et al. 2015). The difference between WCBwf and 
$\mathrm{WCBc}$ is smaller in the $\mathrm{SH}$, with the largest difference during March-May (MAM).

There is a lot of interesting spatial variability in the matching between fronts and WCBs, so in the next sections we show maps of the frequency and proportion of matching. The main focus here is on the winter season in each hemisphere, but we do devote a little discussion to the summer season, and the relevant figures can be found in the supplemental material.

\section{b. Southern Hemisphere}

Figures 4 and 5 show the frequency of occurrence and proportions related to the matching of the objects for June-August (JJA). The frequency of the WCB objects (Fig. 4a) shows a very similar pattern to those in Madonna et al. (2014, their Fig. 5), although the values are larger and the regions more spread out. This is due to the fact that all WCB positions below $790 \mathrm{hPa}$ are considered, and not just the positions at a specific time along the WCB ascent, and also to the smoothing procedure used to generate the objects (see section $2 b$ ). The maxima are located over the Pacific Ocean, to the southeast of South Africa, and in the lee of the Andes.

The frequency of cold fronts matching WCBs and warm fronts matching WCBs (wWCB) is quite low (up to only $6 \%$; Figs. $4 \mathrm{c}, \mathrm{d}$ ). This corresponds to up to $50 \%$ of fronts matched with WCBs (Figs. 5a,b). Considering the strong ascent associated with WCBs, we expect fronts to be more likely to match with WCBs during intensification of the horizontal temperature gradient, so these low values are consistent with a large number of dynamically less active fronts (i.e., those not undergoing strong frontogenesis or undergoing frontolysis) being identified. The frequency of cold fronts matching WCBs during JJA is higher than warm fronts or wind fronts matching WCBs. Between $20^{\circ}$ and $40^{\circ} \mathrm{S}$, there is a band of maximum proportion of fronts matching WCBs (Figs. 5a,b), in a pattern similar to that of WCB frequency.

The frequency of WCBs linked to fronts is fairly evenly distributed between cold and warm fronts (Figs. 4e,f), and the distribution of WCBs associated with wind fronts (Fig. 4i) is very similar to that for cold fronts. It is worth noting that since WCB objects that match a cold and warm front simultaneously are counted both as matching a cold front and matching a warm front, the values in Figs. 4e-h sum to greater than Fig. 4a. There is a relatively large frequency of WCBs linked to warm fronts in the region in the lee of the Andes (up to around $16 \%$; Fig. $4 \mathrm{f}$ ) - a feature that is not so pronounced in the WCBs linked to cold fronts (Fig. 4e). This may be associated with the climatological northerlies resulting from flow blocking by the Andes and the associated transport of warm air (Seluchi and Marengo
2000). These features lead to a higher frequency of warm fronts in this region (Fig. 4b) than in other parts of the $\mathrm{SH}$.

The proportion of WCBs matching cold fronts increases poleward, where there are fewer WCBs and more cold fronts (Fig. 5c). Over South America less than $30 \%$ of WCBs are matched with cold fronts. There is a much higher proportion of WCBs matched with warm fronts over South America (up to 80\%; Fig. 5d). There are also high values in the subtropical Pacific where there are fairly high frequencies of warm fronts. There is a region over the Indian Ocean and Australia where there is a relatively low proportion of WCBs associated with warm fronts (around 30\%) but a high proportion associated with cold fronts (up to $80 \%$ ). This is a region where warm fronts are generally less frequently found, as they tend to occur at higher latitudes (Fig. 4b).

There are a number of regions in the SH during JJA where up to $8 \%$ of the time there are WCBs associated with both cold and warm fronts simultaneously: in the Indian Ocean, Pacific Ocean, and Atlantic Ocean basins (Fig. 4h). Considering the proportion of WCBs associated with both warm and cold fronts simultaneously (Fig. 5e), this is highest at the high latitudes but exhibits considerable zonal variability.

To the east of Australia, there is a distinct region where there is a relatively high frequency of WCBs not linked to either type of front. In fact, there is a higher frequency of nonmatching WCBs in this region than matching (cf. Figs. 4g,h). This corresponds to around $60 \%$ of WCBs in that region not linked to fronts (Fig. 5f). This is a region where there is actually a reasonably high frequency of WCBs and relatively few fronts (Fig. 4b), related to the splitting of the jet in this region during winter (e.g., Risbey et al. 2009). It is of interest to explore the reason for this large number of WCBs in this region of few fronts as well as their characteristics.

An example of the situation of a WCB object not matched with either a cold or warm front from 2 June 1980 is shown in Fig. 6. The potential vorticity (PV) on the 330-K level indicates that there is an upper-level cyclonic PV anomaly aligned with the east coast of Australia. A fairly barotropic cyclone has developed associated with this PV anomaly, with a mean sea level pressure minimum almost collocated with the PV minimum (Fig. 6a) and a closed contour in the 500-hPa geopotential height field (Fig. 6b). The WCB trajectories originate to the northeast of the upper-level PV anomaly and surface cyclone, in a region of very high $850-\mathrm{hPa}$ equivalent potential temperature (Fig. 6b), and then travel in a southeast direction as they undergo ascent (Fig. 6c). Once the trajectories reach the upper levels, 
a) WCB

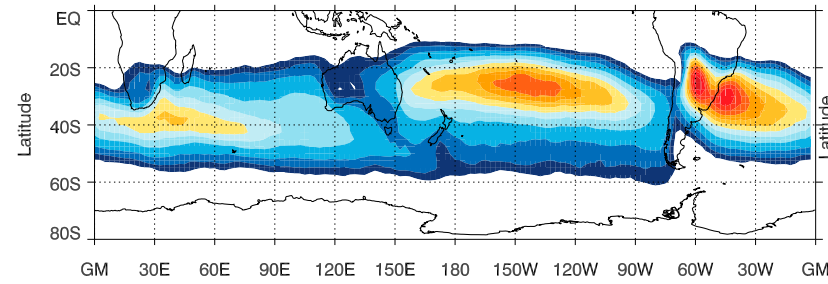

c) Cold front matching WCCB

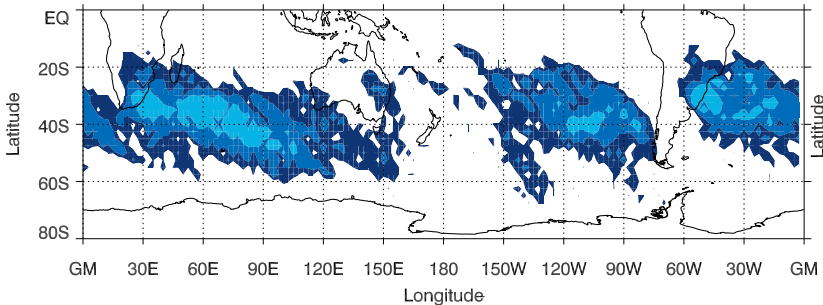

e) WCB matching cold front

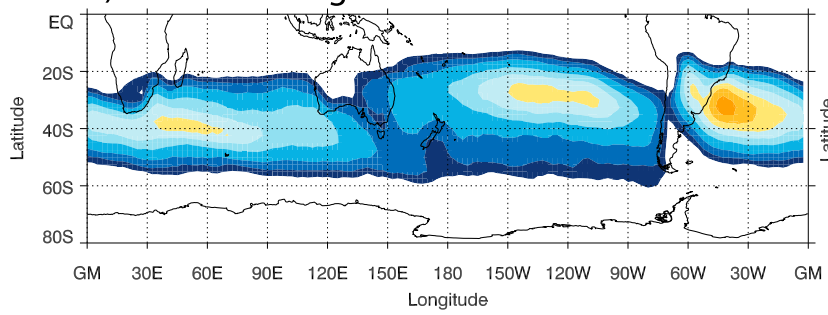

g) WCB matching cold and warm front

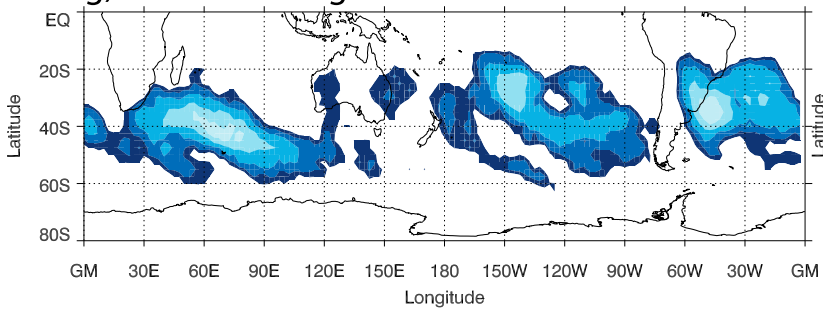

i) Wind front matching WCB

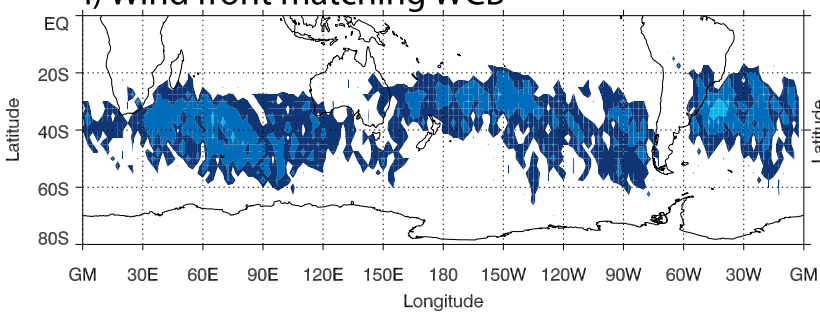

b) Fronts

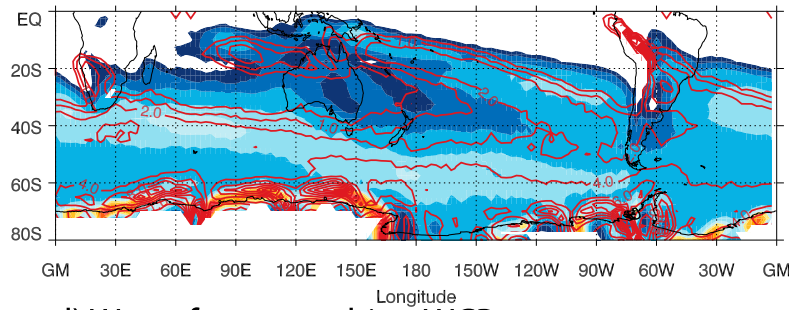

d) Warm front matching WCB

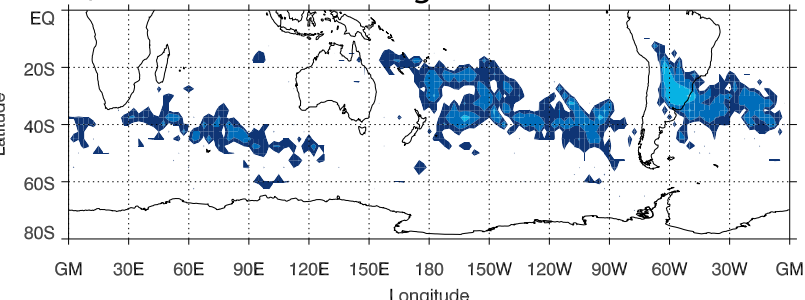

f) WCB matching warm front

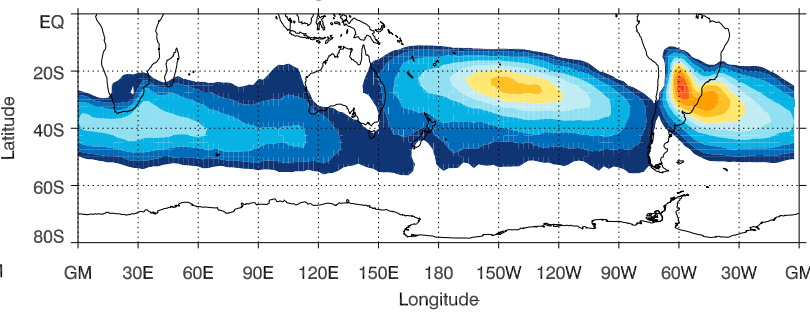

h) WCB matching neither front
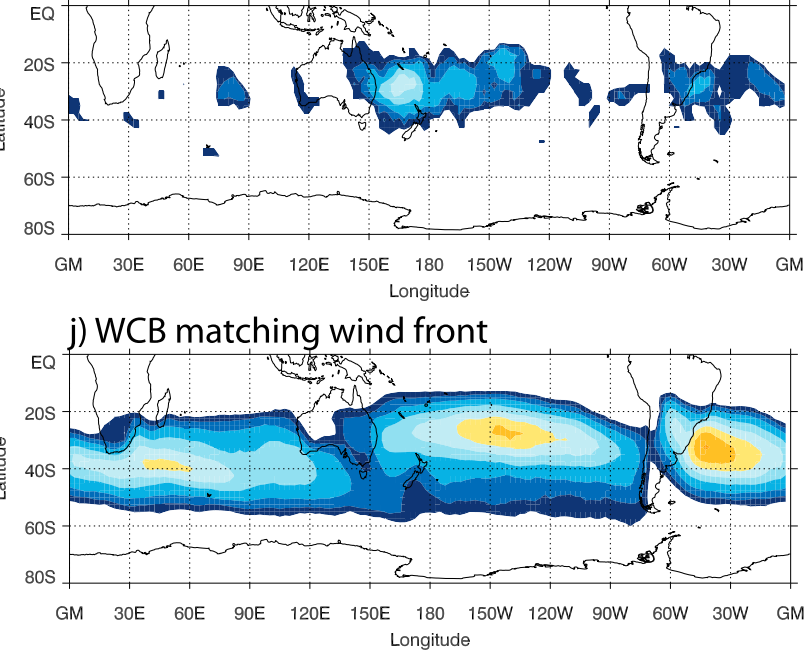

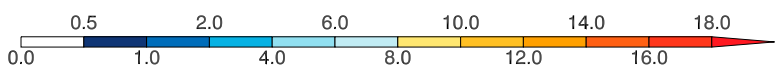

FIG. 4. SH JJA frequency (\% of all times) of (a) WCB objects, (b) fronts (color shading for cold fronts and red contours for warm fronts), (c) cold fronts matching WCBs, (d) warm fronts matching WCBs, (e) WCBs matching cold fronts, (f) WCBs matching warm fronts, (g) WCBs matching both types of fronts, (h) WCBs matching neither type of front, (i) wind fronts matching WCBs, and (j) WCBs matching wind fronts.

they turn anticyclonically and move eastward. There is a weak thermal gradient associated with this system (Fig. 6b) and therefore no fronts are identified in this region. The upper-level PV anomaly acts to destabilize the troposphere below while inducing low-level cyclonic flow. The very warm moist air over the Coral Sea is advected into this region of favorable conditions for ascent and produces the strong WCB. 
a) Cold front matching WCB

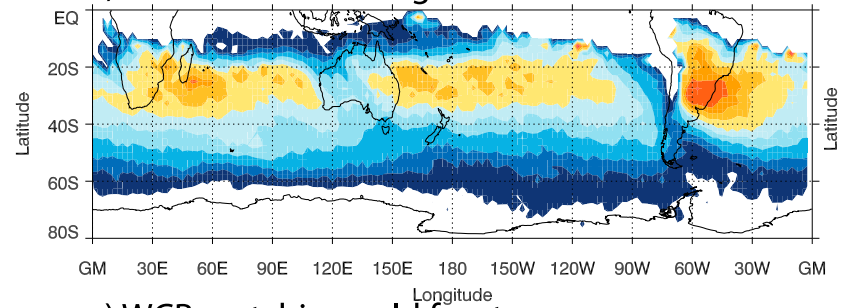

c) WCB matching cold front

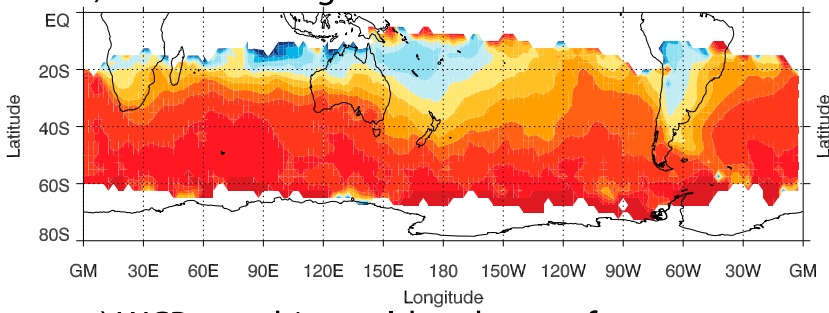

e) WCB matching cold and warm front

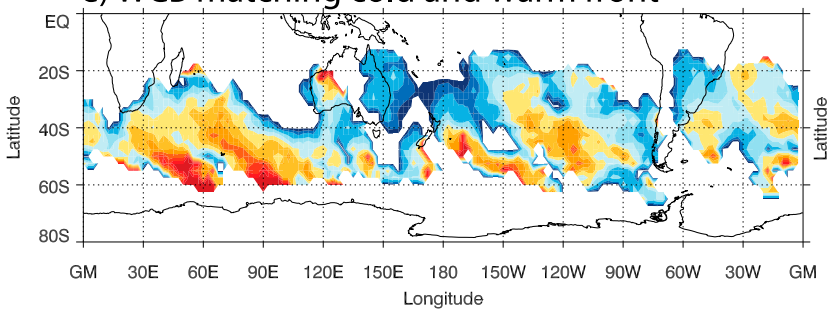

g) Wind front matching WCB

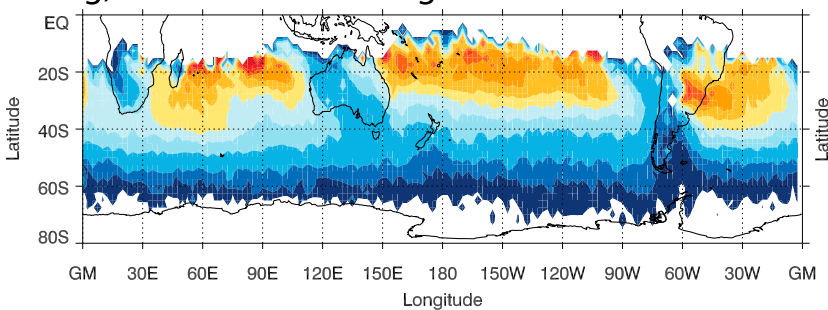

b) Warm front matching WCB

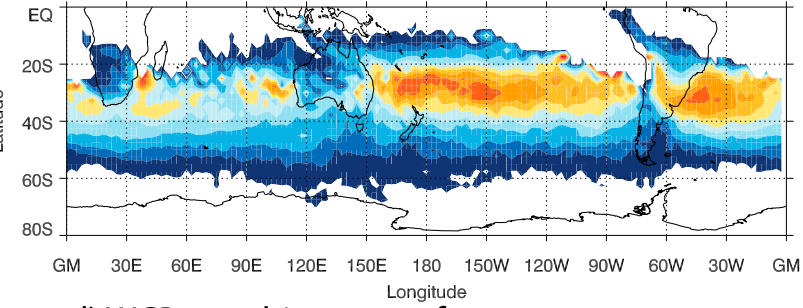

d) WCB matching warm front

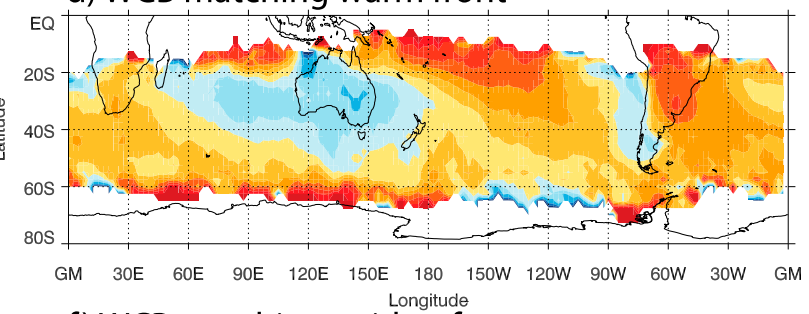

f) WCB matching neither front

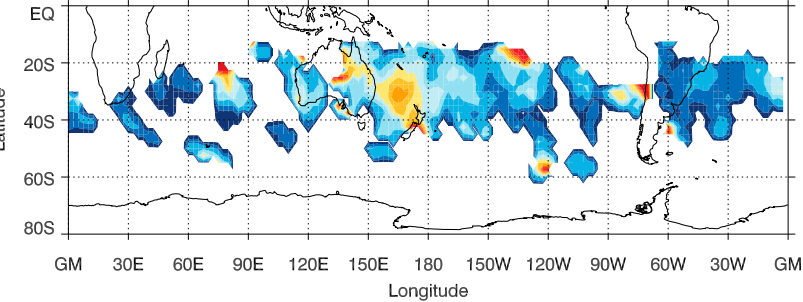

h) WCB matching wind front

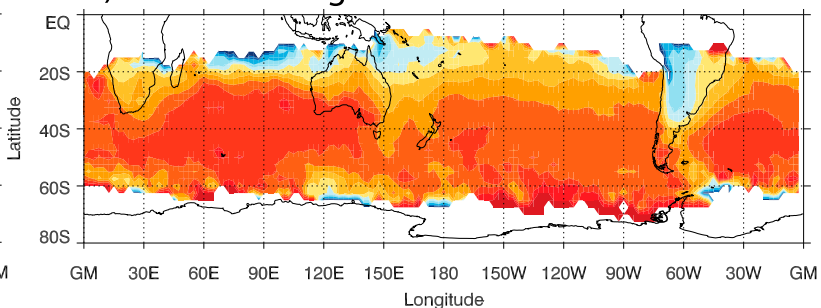

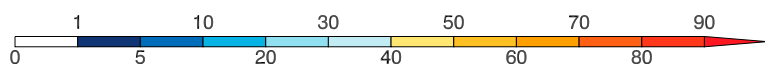

FIG. 5. SH JJA proportion of (a) cold and (b) warm fronts matching WCBs (normalized by the total number of those fronts at the grid point), WCBs matching (c) cold and (d) warm fronts (normalized by the total number of WCBs at the grid point), WCBs (e) matching both types of fronts and (f) matching neither type of front (normalized by the total number of WCBs at the grid point), (g) wind fronts matching WCBs (normalized by the total number of wind fronts at the grid point), and (h) WCBs matching wind fronts (normalized by the total number of WCBs at the grid point).

Many of the individual cases of WCB objects not matching with either cold or warm fronts show patterns similar to the example shown here, with a WCB associated with a barotropic surface low pressure system induced by upper-level cyclonic PV anomalies. This is consistent with this region being a preferred region for cutoff lows (e.g., Ndarana and Waugh 2010).

Considering the summer season in the $\mathrm{SH}$, again the frequency of WCB objects during December-February (DJF) in the SH resembles the frequency of WCB starting positions shown in Madonna et al. (2014, their Fig. 4) and is lower than in winter. The largest maxima are in the lee of the Andes and to the east of the South American continent, with less pronounced maxima to the east of the other continents (see Fig. I in the supplemental material). The WCBs in the lee of the Andes are more frequently linked to warm fronts than cold fronts (or wind fronts) but are also quite frequently not associated with any type of front. In fact, around $60 \%$ of WCBs in the lee of the Andes are associated with warm fronts (Fig. II in the supplemental material). The frequency of fronts matching WCBs is quite low, and the maxima are confined to the regions where the WCBs are most frequent, but in these regions up to 


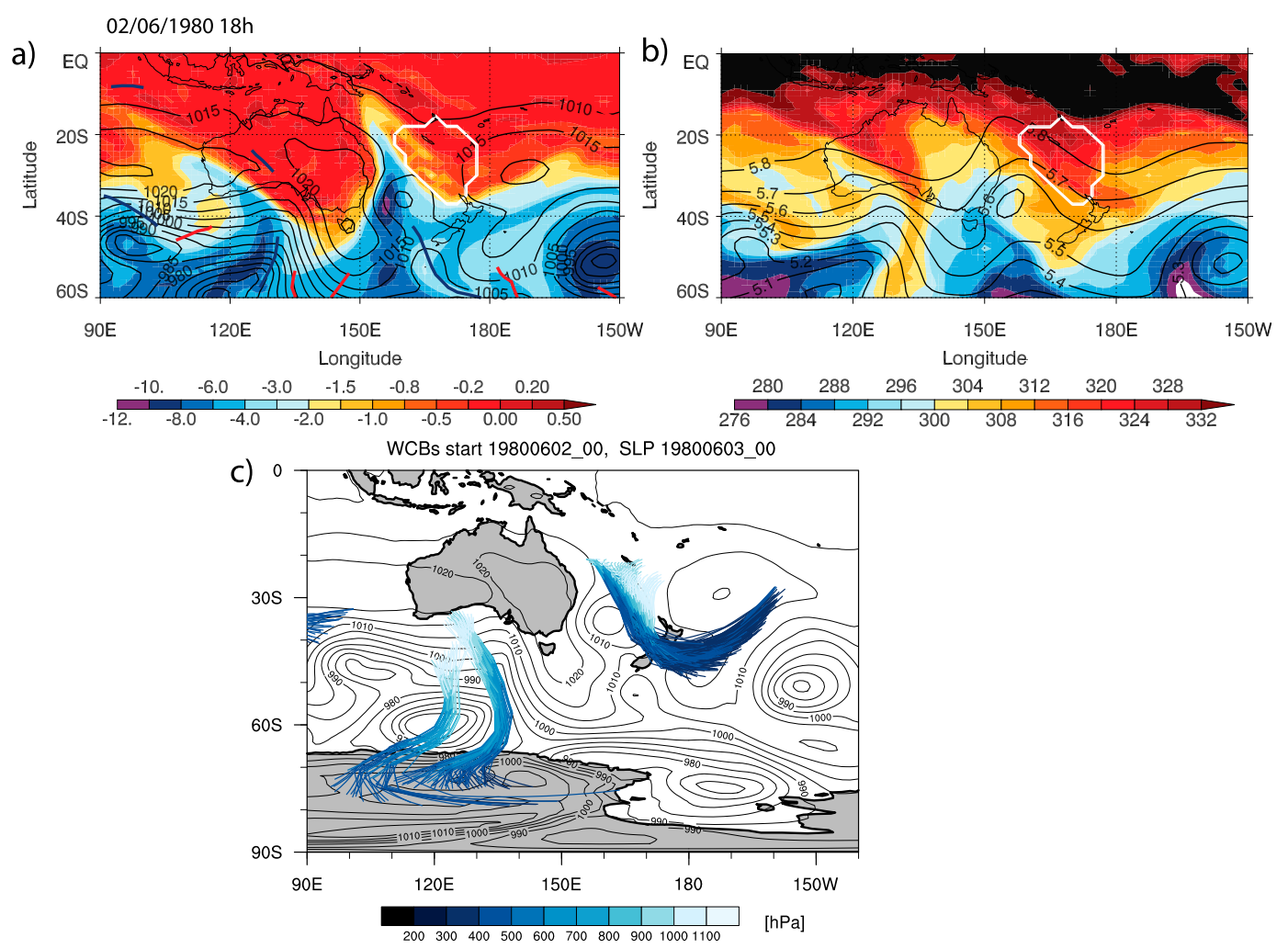

FIG. 6. Example case of a WCB with no matching fronts from 1800 UTC 2 June 1980. (a) PV (PVU; 1 PVU = $10^{-6} \mathrm{~K} \mathrm{~kg}^{-1} \mathrm{~m}^{2} \mathrm{~s}^{-1}$ ) on 330-K surface (colors) with mean SLP (hPa; black contours), (b) 850-hPa equivalent potential temperature (K; colors), and 500-hPa geopotential height ( $\mathrm{km}$; black contours). White contours indicate the position of the WCB, and blue and red thick lines represent the cold and warm fronts, respectively. (c) WCB trajectories starting on 2 June 1980.

around $50 \%$ of fronts are associated with WCBs (Fig. II).

\section{c. Northern Hemisphere}

Figures 7 and 8 show the same analysis for the NH. Maxima of WCB object frequency (Fig. 7a) are seen across the Pacific and Atlantic basin storm-track regions during DJF, with the highest values toward the west of the ocean basins where maxima in cyclogenesis are observed (e.g., Hoskins and Hodges 2002). The frequency of WCB objects is higher in the NH than in most of the $\mathrm{SH}$. Associated with this, the frequency of fronts matched to WCBs is much higher in the NH (Figs. 7c,d,i). The proportion of fronts matched with WCBs is largest (up to $80 \%$ ) in the western parts of the storm tracks (Figs. 8a,b), since this is where more of the dynamically active fronts are found in the major storm development regions. Over much of the NH Atlantic and Pacific Ocean basins, almost all (80\%-100\%) WCBs are associated with cold fronts (and wind fronts; Figs. 8c,h), and $50 \%-90 \%$ of WCBs are associated with warm fronts (depending on the exact location; Fig. 8d). Thus the frequencies of WCBs matching cold and warm fronts (Figs. 7e,f) are very similar in pattern and magnitude to the frequency of WCBs in general. The frequency of matched wind fronts is lower than for cold fronts (cf. Figs. 7c,i), especially at the western edge of the storm tracks. This could be related to a more zonal orientation of fronts in these regions.

There is a high frequency and proportion of WCBs associated with both cold and warm fronts simultaneously (Figs. $7 \mathrm{~g}$ and $8 \mathrm{e}$ ), particularly in the west of the ocean basins, and a relatively low frequency of WCBs not associated with either type of front (Figs. 7h and 8f). This indicates that there is less frequent occurrence in the $\mathrm{NH}$ of the type of low pressure feature with weak temperature gradients seen in the SH. Detailed investigation of this aspect of extratropical cyclones is beyond the scope of the present study.

In the NH summer (JJA), the frequency of all the different objects is much lower (see Fig. III in the supplemental material). The WCB objects are more tightly constrained to the western edges of the storm tracks. The proportion of WCBs linked to cold and warm fronts is still very high (Fig. IV in the supplemental material), although the frequencies are low. The proportion of 
a) WCB

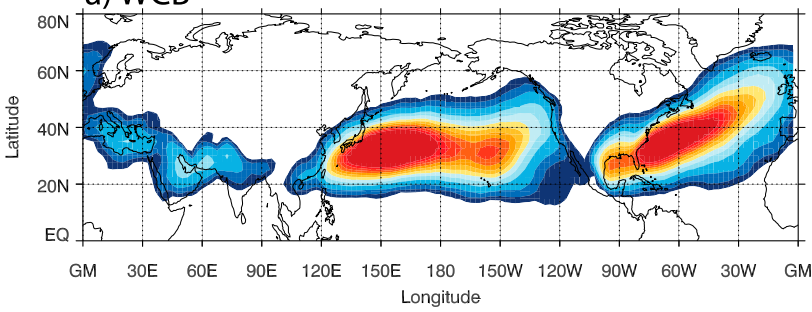

c) Cold front matching WCB

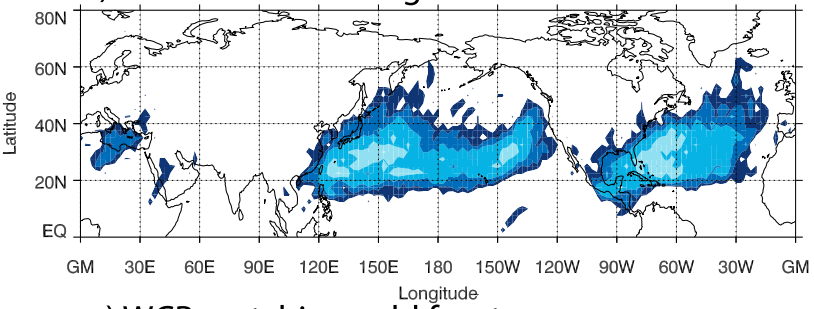

e) WCB matching cold front

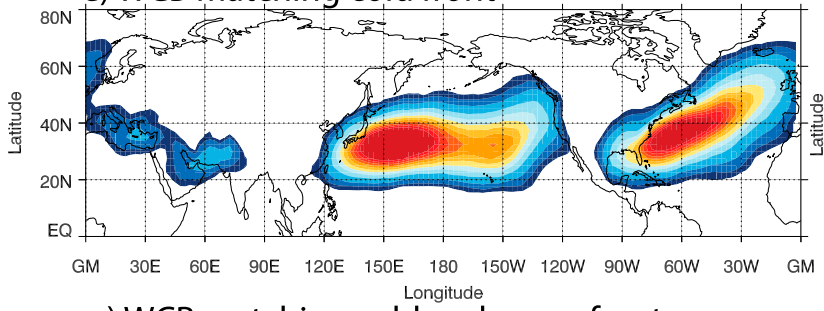

g) WCB matching cold and warm front

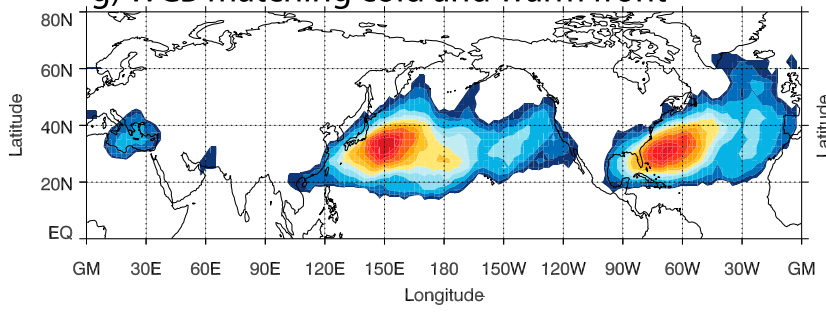

i) Wind front matching WCB

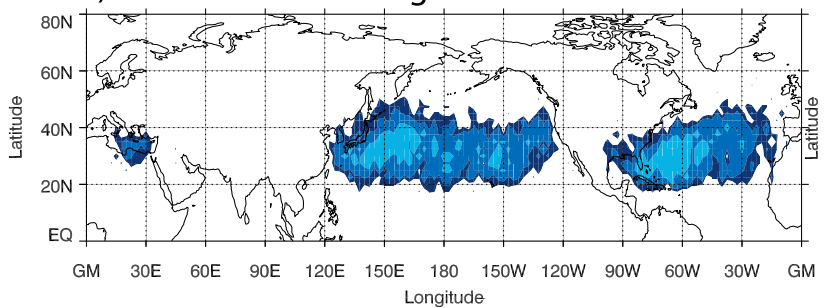

b) Fronts

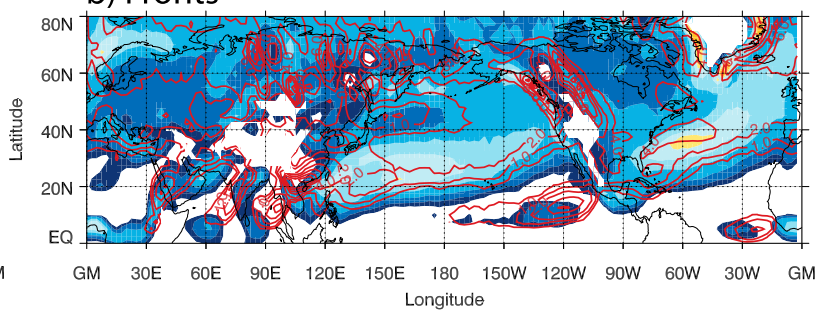

d) Warm front matching WCB

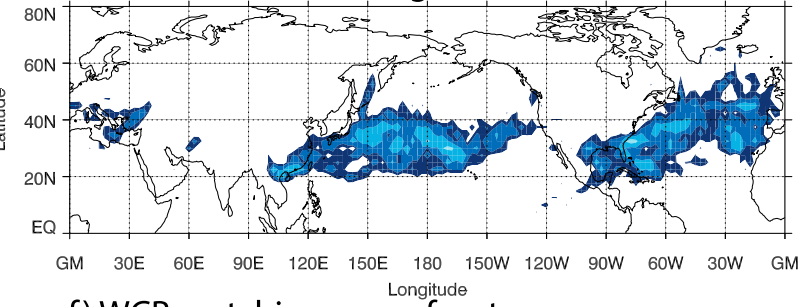

f) WCB matching warm front

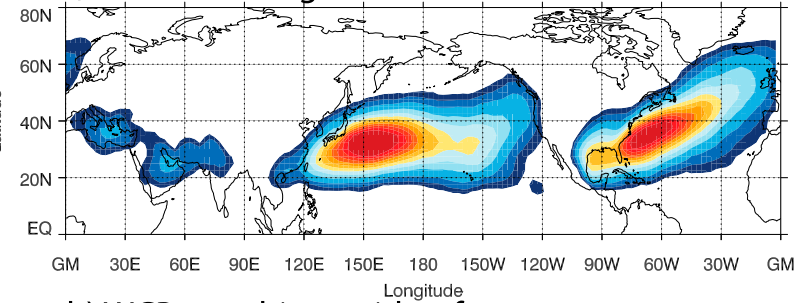

h) WCB matching neither front
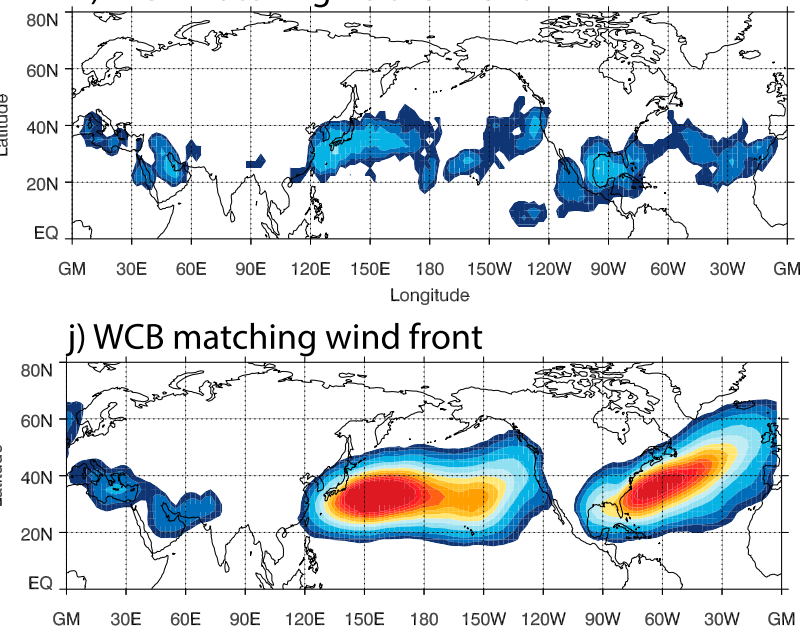

GM $30 \mathrm{E} \quad 60 \mathrm{E}$ 90E 120E 150E 180 150W 120W 90W 60W 30W GM Longitude

FIG. 7. As in Fig. 4, but for NH DJF.

WCBs linked to the wind fronts is lower, associated with the relatively fewer wind fronts identified during JJA.

\section{d. Impact of different WCB heights}

To investigate the relationship between WCBs and fronts at different times in the WCB life cycle, we created WCB objects from between 790 and $600 \mathrm{hPa}$ to represent the WCBs as they go through their midtropospheric ascent. These midlevel WCB objects have been linked to cold and warm fronts in the same way as the lower-level objects. Figure 9 shows the difference in the summary statistics (proportion of fronts matched with WCBs and proportion of WCBs matched with fronts) between the midlevel and low-level objects. The differences are calculated as demonstrated for the case of cold fronts matching WCBs: 
a) Cold front matching WCB

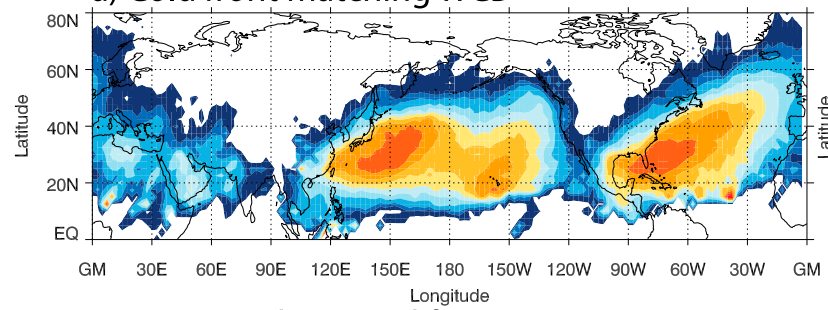

c) WCB matching cold front

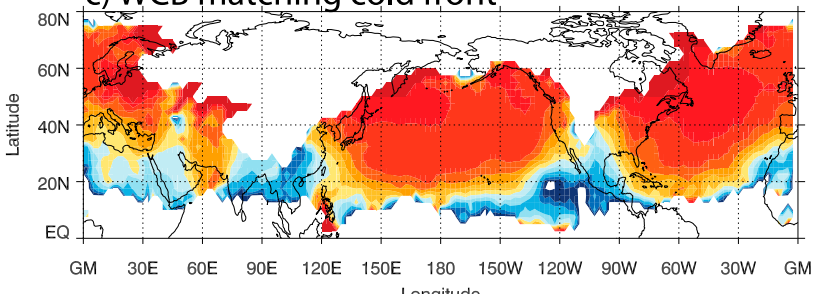

e) WCB matching cold and and warm front

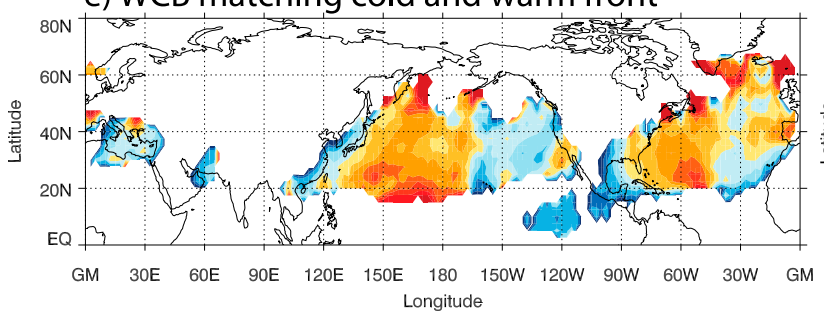

g) Wind front matching WCB

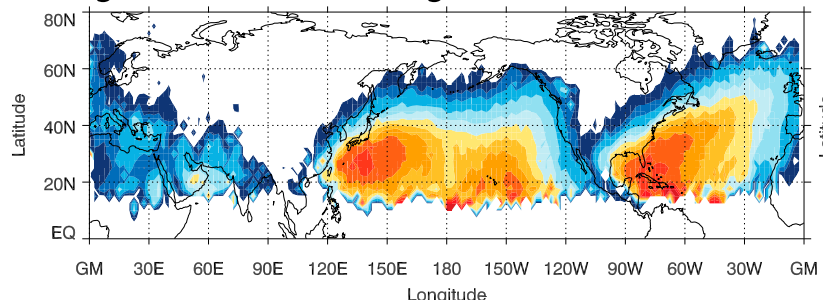

b) Warm front matching WCB

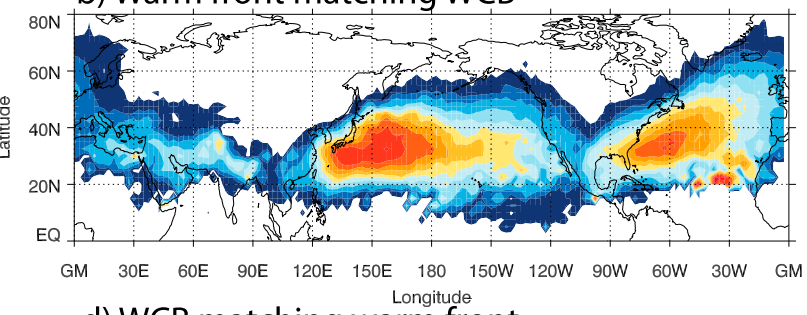

d) WCB matching warm front

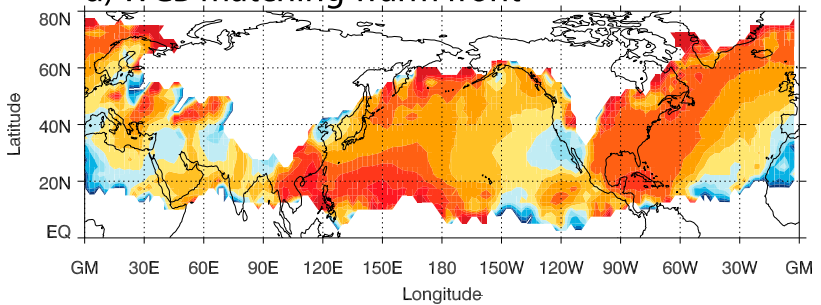

f) WCB matching neither front

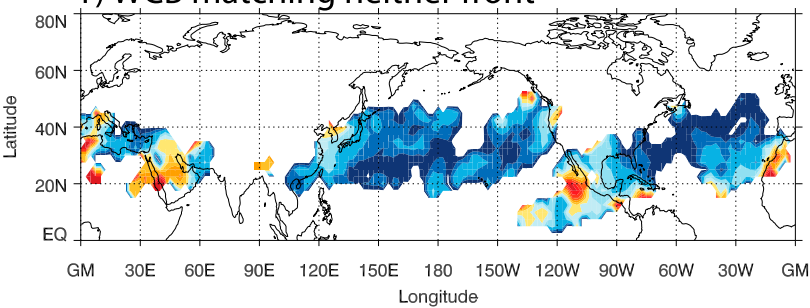

h)WCB matching wind front

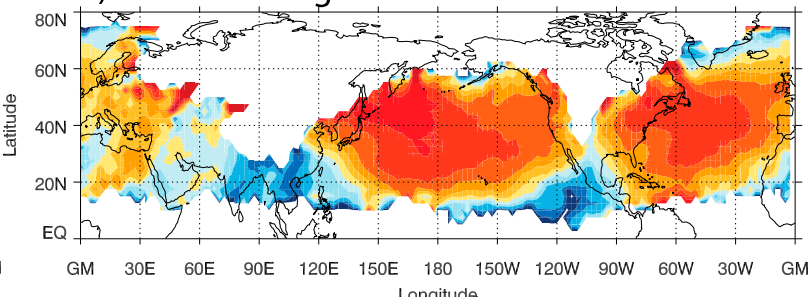

90

FIG. 8. As in Fig. 5, but for NH DJF.

$$
\delta P=\left(F_{\mathrm{cWCB}} / F_{c}\right)_{\mathrm{mid}}-\left(F_{\mathrm{cWCB}} / F_{c}\right)_{\mathrm{low}},
$$

where $\delta P$ is the difference in proportions, $F$ is the frequency, cWCB represents cold fronts matching WCBs, and $c$ represents cold fronts. In the $\mathrm{SH}$, on an annual basis, slightly more WCBs overlap with fronts during the midtropospheric ascent compared to their origin in the lowest troposphere, especially warm fronts. During JJA more WCBs are related to warm fronts and fewer to cold fronts in the midlevels. In the $\mathrm{NH}$, annually the WCBs in the lower troposphere overlap with fronts more often than during their midtropospheric ascent; however, during DJF this is the other way around. These differences between the $\mathrm{NH}$ and $\mathrm{SH}$ suggest that there are some differences between frontal structure and ascent patterns in the two hemispheres. For example, there may be a different split between the anabatic- and katabatic-type fronts (Sansom 1951; Browning 1986). This is an interesting question that would require further analysis and is beyond the scope of the current study.

The ratio of $\mathrm{WCBc}$ to $\mathrm{WCB} w$ gives a measure of the relative importance of the two types of fronts. For the lower-level WCB objects annually this ratio is $1: 1$ in the $\mathrm{NH}$ and 1:3 in the SH. For the midlevel WCB objects the values are also 1:1 in the $\mathrm{NH}$ and 1:3 in the $\mathrm{SH}$. This shows that in an annual average sense, the relative importance of warm and cold fronts is the same at lower and midlevels. The largest difference in the ratio between low-level objects and midlevel objects occurs during JJA in the $\mathrm{SH}$, although the difference is still only 0.1 . 


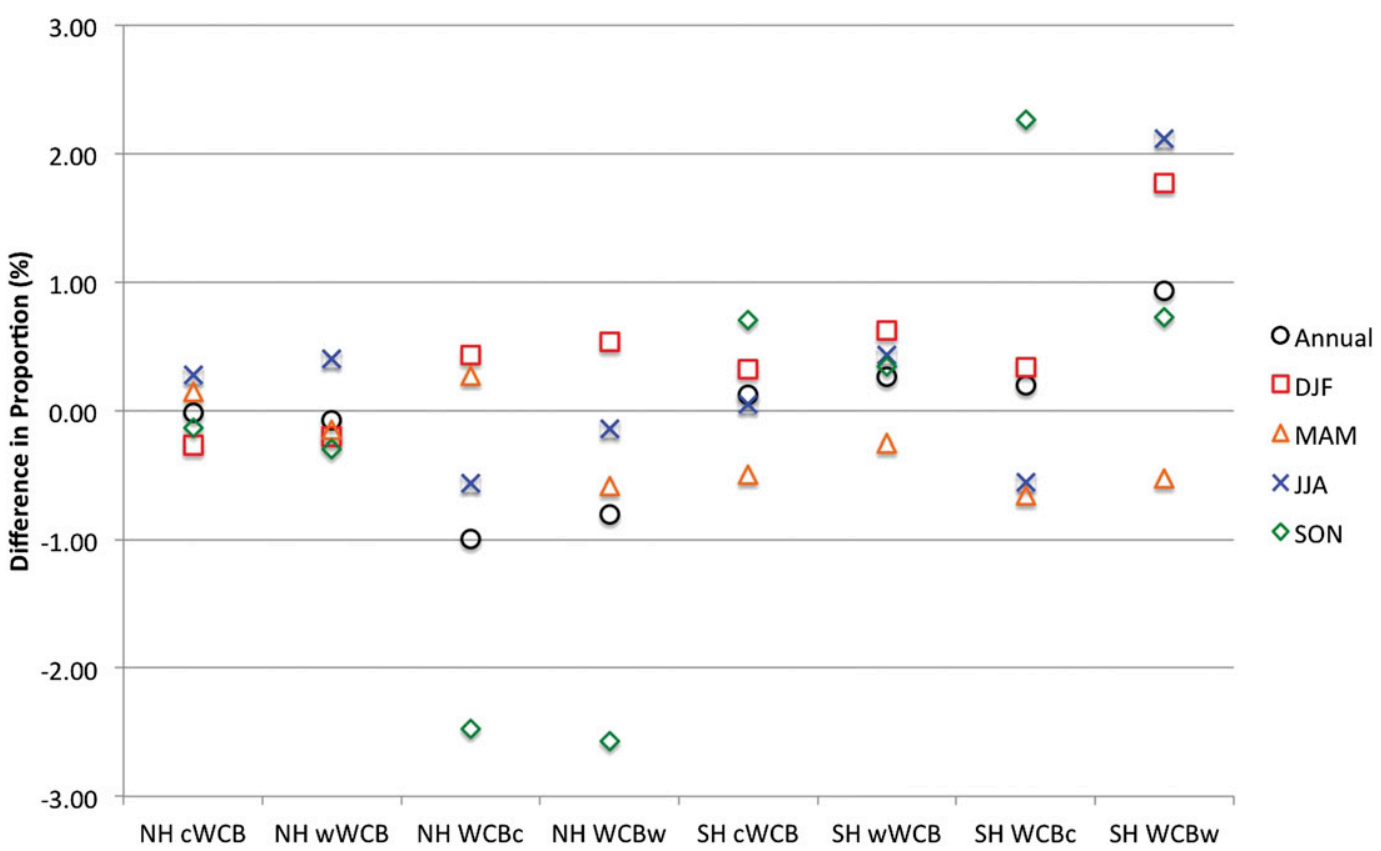

FIG. 9. Graph showing the difference in the summary statistics between midlevel WCB objects and low-level WCB objects for the relationship between WCB objects and fronts. Proportion of objects associated with other objects (cWCB, wWCB, WCBc, and WCBw).

Although on average over the hemispheres the difference in the ratio of $\mathrm{WCBc}$ to $\mathrm{WCBw}$ between low and midlevels is very small, there is some interesting detail in the spatial distribution. Figure 10 shows the wintertime (NH DJF and SH JJA) difference (low level minus midlevel) in the ratios of $\mathrm{WCBc}$ to $\mathrm{WCBw}$. During DJF, there is a very high frequency of warm fronts found over land along the U.S. West Coast (higher than for cold fronts; Fig. 7b). The WCB starting locations (and therefore the position of the lowlevel WCB objects) are mostly located over the ocean to the west (see Madonna et al. 2014), where cold fronts are more frequent. As the WCB trajectories beginning close to the coast rise up and move eastward, they encounter more frequent warm fronts. Over the rest of the hemisphere, there is very little impact of considering midtropospheric ascent. This suggests that in most locations, the WCBs starting close to only a cold front stay close to only a cold front as they go through their ascent, and the same for warm fronts, consistent with the trajectories seen in Wernli (1997). In the $\mathrm{SH}$ the positive values are more widely spread and are larger, especially at higher latitudes (between $40^{\circ}$ and $60^{\circ} \mathrm{S}$ ). This suggests that in the $\mathrm{SH}$, the WCBs tend to rise up over the warm frontal region later in the life cycle of cyclones, consistent with the transition from anabatic- to katabatic-type fronts (Sansom 1951). The pattern relates quite strongly to the pattern of lysis density in the SH (Simmonds et al. 2003; Hoskins and Hodges 2005).

\section{Link to extreme precipitation}

To understand the importance of the linkage between WCBs and fronts for extreme precipitation events, we have linked these with the synoptic features (e.g., cold front with or without a matched WCB). Since the wind fronts and the cold fronts demonstrate very similar patterns in terms of the matching with WCBs, only the cold and warm fronts have been used in this section for brevity.

\section{a. Southern Hemisphere}

Figures 11a-e show the SH winter (JJA) proportion of extreme precipitation events associated with cold fronts (Fig. 11a), warm fronts (Fig. 11b), cold fronts with matched WCBs (Fig. 11c), and warm fronts with matched WCBs (Fig. 11d). Figures 11e,f show the proportion of frontal extreme precipitation events that also have matched WCBs - that is, the ratio of Fig. 11c to Fig. 11a for cold fronts (Fig. 11e) and the ratio of Fig. 11d to Fig. 11b for warm fronts (Fig. 11f), shown as a percentage.

The proportion of extreme precipitation events associated with cold fronts (Fig. 11a) reaches a maximum of around $80 \%$ in the Indian Ocean sector and is generally 

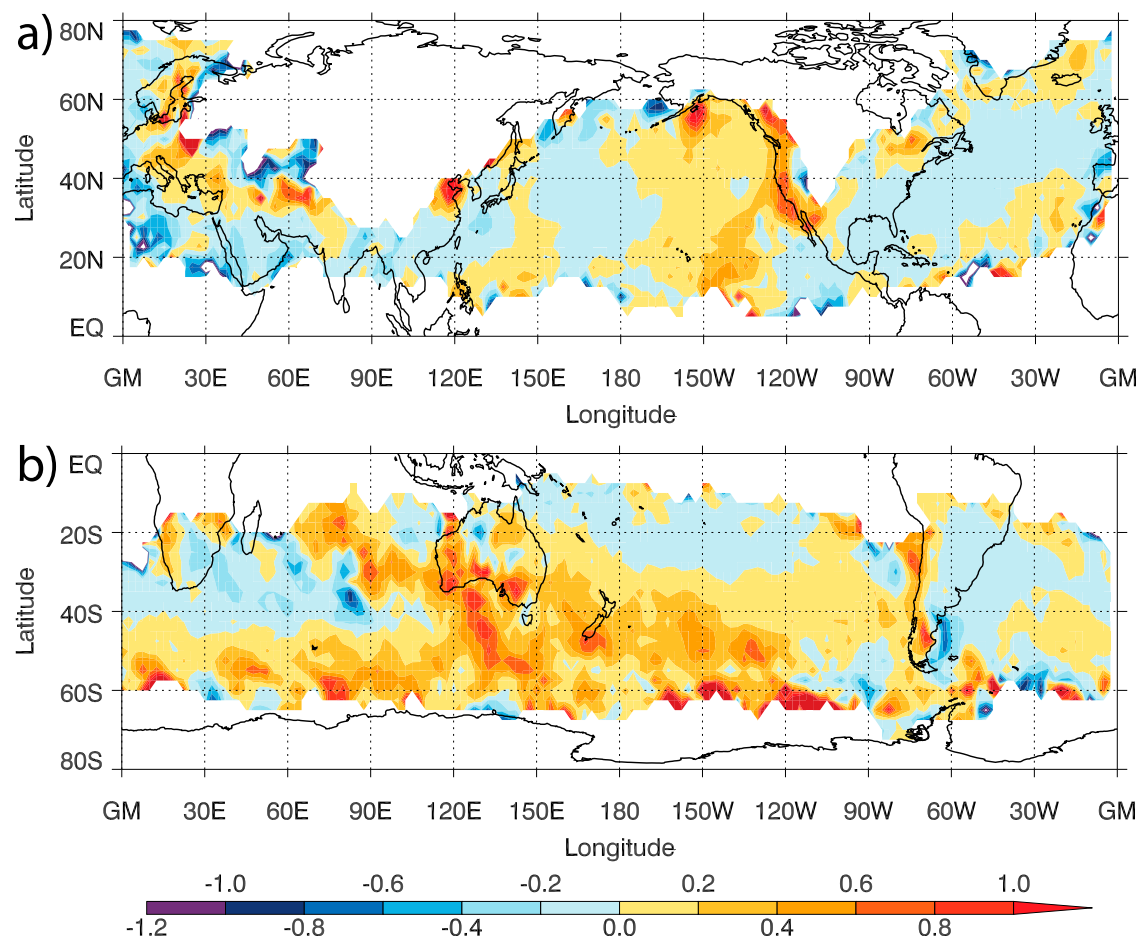

FIG. 10. Difference in the ratio of WCBs linked to cold fronts to WCBs linked to warm fronts for the low-level WCB objects (up to $790 \mathrm{hPa}$ ) and higher-level WCB objects (790-600 hPa) for (a) $\mathrm{NH}$ and (b) SH. Red colors indicate a stronger relative importance of warm fronts at upper levels, and blue colors indicate a stronger relative importance of cold fronts at upper levels (compared to lower levels).

high in a band from south of South Africa to south of New Zealand. In that region the proportion of extreme precipitation events associated with cold fronts matched with WCBs is up to $60 \%$ (Fig. 11c). The patterns are quite similar between the cold fronts and the cold fronts with matched WCBs in the Indian Ocean sector. Over the South Pacific, the patterns look different due to the fact that the WCB frequency drops off dramatically south of $60^{\circ} \mathrm{S}$.

The proportion of extreme precipitation events matched with warm fronts is highest around the Antarctic coast (Fig. 11b). This is likely associated with the identification of many warm fronts at the strong temperature gradient between sea and ice in this region that would not be regarded as truly synoptic features. It can also be noted that in this region the 99th percentile of precipitation is low compared to lower latitudes (below $10 \mathrm{~mm}$ ). There is a region extending from the Indian Ocean to New Zealand, across the south of Australia, where a relatively low percentage of extreme precipitation events are associated with warm fronts (roughly coinciding with the region where extreme precipitation is associated with cold fronts and/or cold fronts are associated with WCBs). A high proportion of the extreme precipitation events associated with warm fronts with matched WCBs is found in the central Pacific region, in the lee of the Andes, and to the east of South America (Fig. 11d). In these regions over $90 \%$ of the warm-front-related extreme precipitation events have matched WCBs. In some locations (mostly where the WCBs are most frequent), around $90 \%$ of the extreme precipitation events associated with fronts have matched WCBs (Figs. 11e,f).

To understand whether the presence of a WCB associated with a front influences the likelihood of the front producing an extreme precipitation event, we have calculated the percentage of cold fronts and warm fronts that are associated with extreme precipitation events (cx and wx, respectively) and the percentage of cold and warm fronts that have matched WCBs with extreme precipitation (cxWCB and wxWCB, respectively). The average value of cx between $20^{\circ}$ and $60^{\circ} \mathrm{S}$ (the region most influenced by WCBs) during JJA is $2.0 \%$, whereas the value of cxWCB is $5.3 \%$. For the warm fronts, wx is $3.8 \%$ and $w x W C B$ is $10.8 \%$. This indicates that on average, fronts matched with WCBs are greater than 2.5 times more likely to produce an extreme precipitation event than fronts that are not associated with WCBs. In some regions they can be up to 10 times as likely to produce 
a) Extreme matching cold front

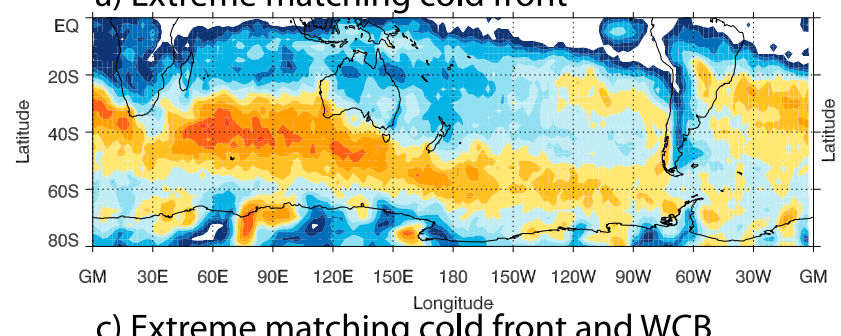

c) Extreme matching cold front and WCB

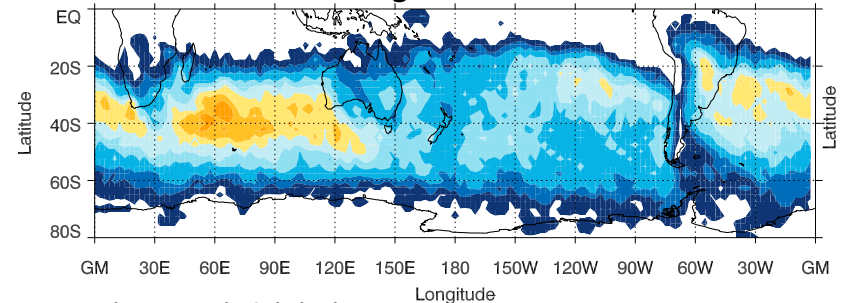

e) Ratio (c/a) (\%)

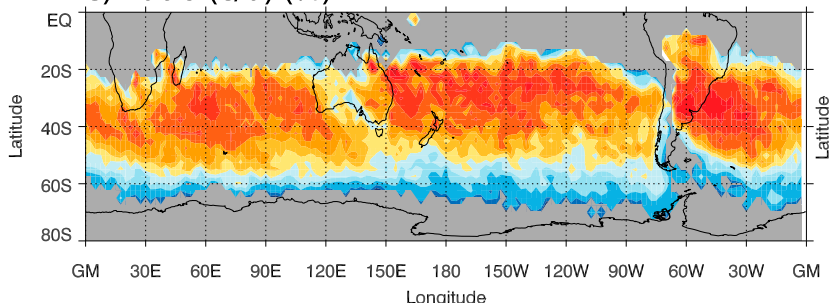

b) Extreme matching warm front

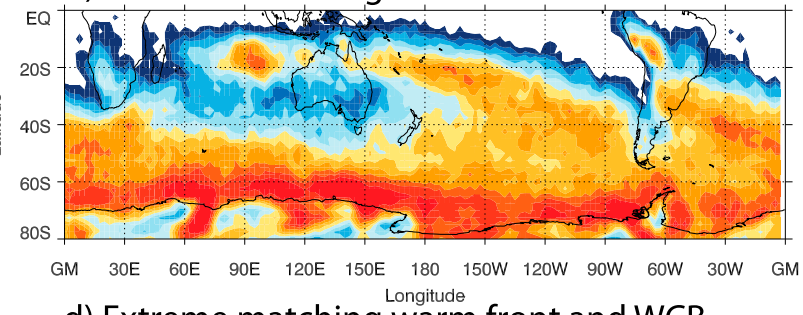

d) Extreme matching warm front and WCB

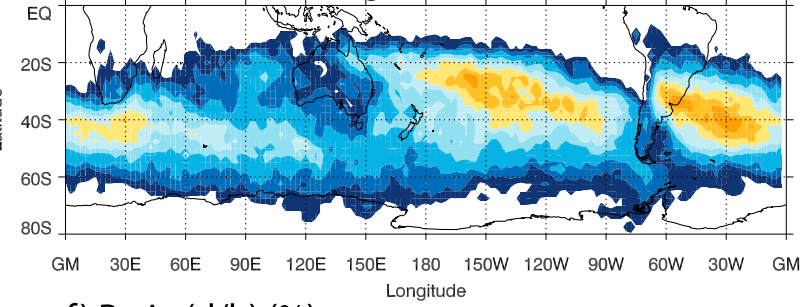

f) Ratio (d/b) (\%)

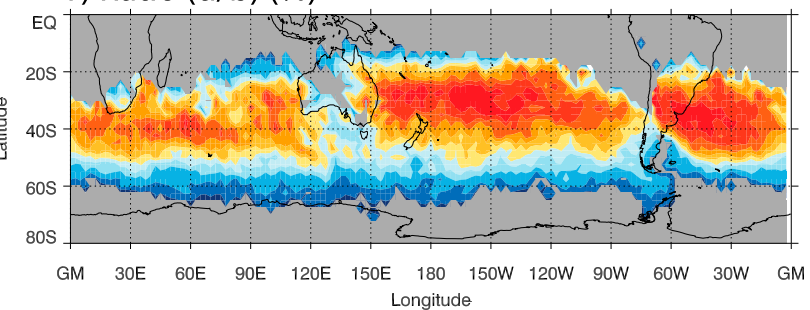

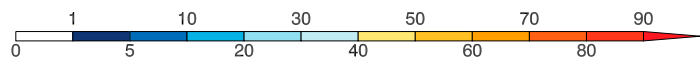

FIG. 11. JJA percentage of extreme precipitation events associated with (a) cold fronts, (c) cold fronts with matching WCB, (b) warm fronts, and (d) warm fronts with matching WCB. JJA proportion of (e) cold fronts with extremes that have matching WCBs (ratio cxWCB/cx as a percentage) and (f) warm fronts with extremes that have matching WCBs (ratio wxWCB/wx as a percentage). In (e) and (f), the grid boxes where (c) and (d), respectively, are less than $5 \%$ are masked in gray.

extreme precipitation events (not shown). This is not surprising given the large condensational heating that occurs along the WCB trajectories (Madonna et al. 2014).

\section{b. Northern Hemisphere}

In the $\mathrm{NH}$ the wintertime (DJF) proportion of extreme precipitation events associated with fronts (Figs. 12a,b) is similar to that in the SH. Over the North Atlantic and North Pacific Ocean basins, this reaches about $90 \%$. Most of the extreme precipitation events associated with cold fronts also have matched WCBs (Fig. 12e). The proportion of extreme precipitation events associated with warm fronts is highest over the strong baroclinic zones of the Gulf Stream and the Kuroshio, as well as at higher latitudes over land and at the ends of the storm tracks (Fig. 12d). The high matching of precipitation extremes and warm fronts over land is consistent with the much higher frequency of warm fronts than cold fronts in these regions (Fig. 7b). Since the precipitation extremes we are considering here are large scale and span 6-h periods, it might be expected that the precipitation extremes be more strongly associated with warm fronts in the regions where cyclones are mature. A very large proportion of the extreme precipitation events associated with warm fronts are also associated with WCBs but only between around $20^{\circ}$ and $60^{\circ} \mathrm{N}$ (Fig. 12). At the higher latitudes, there are no WCBs detected by this method (i.e., no trajectories satisfy the $600-\mathrm{hPa}$ ascent threshold).

The average values of cx and cxWCB between $20^{\circ}$ and $60^{\circ} \mathrm{N}$ are $1.8 \%$ and $8.7 \%$, respectively, and average values for wx and wxWCB are $2.8 \%$ and $9.7 \%$, respectively. This indicates that fronts themselves are not strong predictors for precipitation extremes since a value of $1 \%$ would be the value expected purely by chance for the 99th-percentile extremes. However, during winter in the $\mathrm{NH}$, cold fronts are almost 5 times more likely to produce an extreme precipitation event if they are associated with a WCB. On the northern edges of the storm tracks, a large proportion of the fronts linked to WCBs are associated with extreme precipitation events. In these regions, the matching with a WCB makes the cold fronts more than 10 times as likely to be associated with an extreme precipitation event 
a) Extreme matching cold front

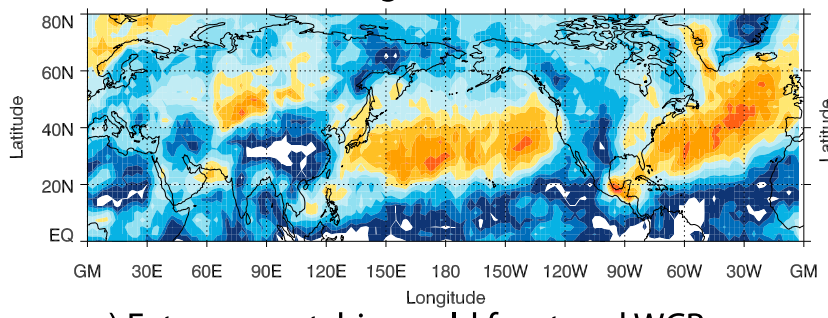

c) Extreme matching cold front and WCB

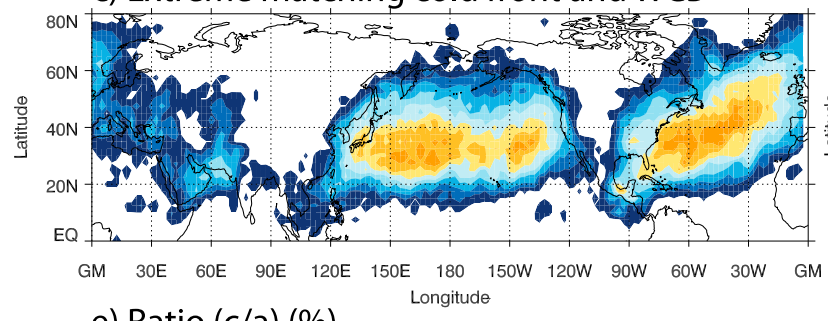

e) Ratio (c/a) (\%)

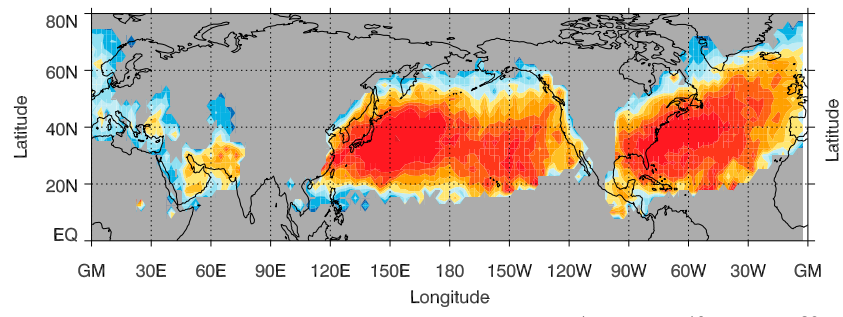

b) Extreme matching warm front

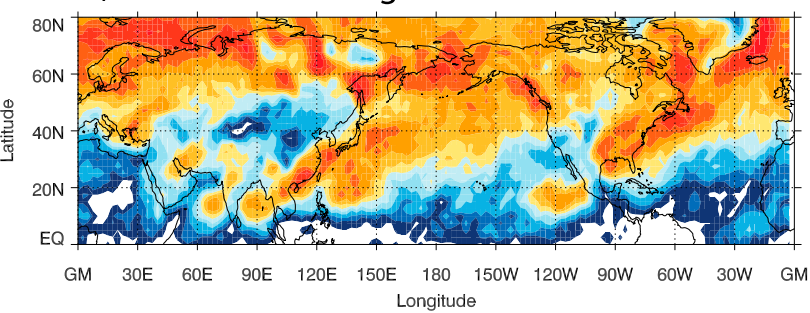

d) Extreme matching warm front and WCB

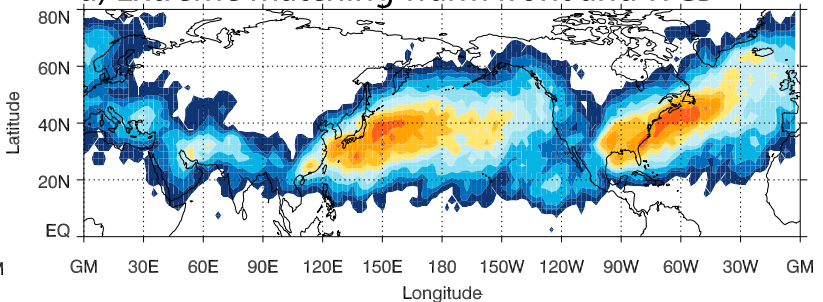

f) Ratio (d/b) (\%)

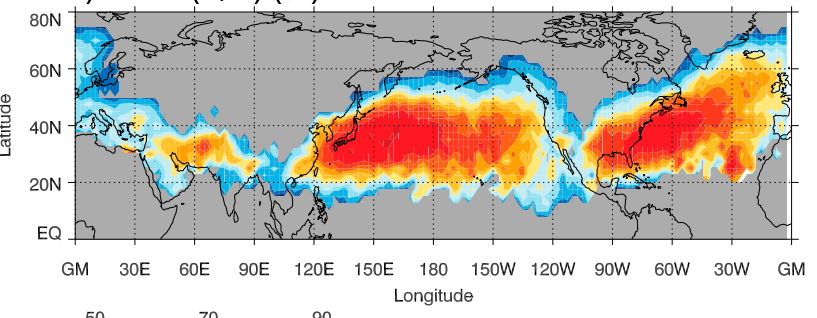

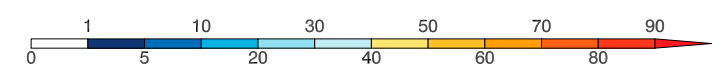

FIG. 12. As in Fig. 11, but for DJF.

(not shown). The linking with a WCB has a slightly smaller effect on the likelihood of a warm front being associated with an extreme precipitation event.

\section{Summary and discussion}

We have brought together the objective front identification methods of Berry et al. (2011) and Simmonds et al. (2012) and the WCB climatology of Madonna et al. (2014) to investigate the link between fronts and WCBs and the influence of this link on extreme precipitation. We identified low-level WCB objects as groups of grid points influenced by WCB trajectories located below $790 \mathrm{hPa}$. These were matched to fronts using a simple overlap technique.

The first questions we set out to answer were, how often are WCBs associated with fronts and fronts associated with WCBs, and what is the distribution between cold and warm fronts? The main conclusions related to these questions are as follows:

- During winter in each hemisphere, about $10 \%$ of cold fronts, about $8 \%$ of warm fronts, and about $20 \%$ of wind fronts are linked with WCBs (Fig. 3).
- About $70 \%$ of WCBs are linked to cold fronts during winter, and about $50 \%$ of WCBs are associated with warm fronts in the $\mathrm{NH}$ winter and $42 \%$ in the $\mathrm{SH}$ winter (Fig. 3).

- WCBs in the NH winter quite frequently occur with both matching cold and warm fronts, whereas this is less frequent in the SH (Figs. 4 and 7).

- In the region centered on the Tasman Sea there are frequent WCBs with no associated fronts. These appear to be related to cutoff low pressure systems (Fig. 6), which preferentially occur in this region (Ndarana and Waugh 2010).

Previous studies have shown that there are a number of different ascending airflows that can be found in extratropical cyclones-for example, the rearward- and forward-sloping WCBs detailed in the conceptual models of Browning (1986) and further identified using Lagrangian trajectory analysis by Wernli (1997). Our results show from a climatological perspective that when the WCBs are in the lower troposphere, they are slightly more often associated with cold fronts, consistent with the rearwardsloping anabatic front situation Browning (1986).

Despite many more cold fronts being identified than wind fronts and small shifts in the exact position of the fronts (Schemm et al. 2015) relative to a cyclone, the 
frequency of WCBs matching cold fronts or wind fronts and the frequency of these types of fronts matching WCBs are very similar. This suggests the matching procedure, when considering frequency, is not sensitive to the front identification method.

The objective method used to identify the WCBs and the thresholds used will also influence the results of this type of study. We performed a sensitivity test to the WCB ascent threshold. This ascent threshold is set at $600 \mathrm{hPa}$ in Madonna et al. (2014) and our study and identifies the trajectories with maximum ascent, which is related to the key characteristic of a WCB of maximum precipitation. Trajectories were identified also using a $500-\mathrm{hPa}$ threshold. The number of wind fronts that matched these airstreams characterized by a weaker ascent than WCBs doubled, but the number of these airstreams related to the fronts stayed almost constant. This indicates that as these ascending airstream objects become larger they are sometimes matched to several fronts at the same time. Also, some new objects that are matched with fronts are detected. To reduce the effect of the first reason, a threshold of $600 \mathrm{hPa}$ was retained.

For an answer to the second question of whether the stage in the life cycle of the WCB influences the relationships between WCBs and fronts, we found that the proportion of midlevel WCB objects associated with fronts is very similar to the low-level WCB objects. Therefore, the WCBs are already matched with fronts early in their life cycle. The relative importance of the warm fronts to the midlevel WCB objects is greater than to the low-level WCB objects at the eastern ends of the storm tracks where the cyclones are generally more mature.

Finally, we linked the fronts and WCB objects to extreme precipitation events (defined at each grid box as events exceeding the 99th percentile of precipitation). We found that in the region where WCB objects are most frequent, almost all the fronts associated with extreme precipitation events had associated WCBs, and fronts with associated WCBs are between 2 and 10 times more likely to be associated with an extreme precipitation event than other fronts. These results can be explained by the nature of WCBs, which to ascend to $600 \mathrm{hPa}$ need steep isentropes (e.g., a front) and moisture. The large volumes of moisture transported by the WCBs are associated with anomalously strong evaporation (Pfahl et al. 2014). Latent heat is released during the ascent, leading to a change in the potential temperature of more than $20 \mathrm{~K}$ (Madonna et al. 2014) and consequently leading to intense precipitation formation. Pfahl et al. (2014) found that more than $60 \%$ of extreme precipitation events in the storm-track regions are related to WCBs. Here we corroborate these findings by showing that most of those WCBs also have fronts, which provide the ingredients for a steeper ascent.
Lavers and Villarini (2013) showed that a large proportion of annual maximum precipitation events in Europe are associated with atmospheric rivers. Our results are consistent with this, in that the WCBs may be feeding off the moisture located in the atmospheric rivers (e.g., Sodemann and Stohl 2013). Dacre et al. (2015) suggest, however, that atmospheric rivers are actually formed by subsequent extratropical cyclones and the WCBs located their warm sector. Irrespective, there is a clear relationship between WCBs and atmospheric rivers, and this study reconfirms the importance of these for extreme precipitation events.

The importance of the features within extratropical cyclones for producing extreme precipitation means that climate models need to be able to correctly represent the relationship between these features and the precipitation in order to have confidence in future midlatitude rainfall projections. Although climate models can capture the main dynamical features of extratropical cyclones (Catto et al. 2010), it is not clear whether they would capture the relationship between the WCB features, fronts, and extreme precipitation events. Extratropical cyclones and their associated features are likely to undergo changes in their preferred locations in a future warmer climate (e.g., Chang et al. 2013; Zappa et al. 2013; Catto et al. 2014; Rudeva and Simmonds 2015), and the relationship between the dynamical features and the associated precipitation may change. The evaluation of present-day simulations and investigation of projections of these features will be the focus of future work.

Acknowledgments. This study was supported by the Australian Research Council through the Discovery Early Career Researcher Award Grant DE140101305. Part of the work of EM has been funded by the Swiss National Science Foundation (Project 200021-130079). The study was also facilitated by a visit of EM to Melbourne University and of JLC to ETH Zurich. The front identification algorithm was kindly provided by Gareth Berry. The authors thank Heini Wernli for helpful and insightful comments on an earlier version of the manuscript. ERA-Interim data are available online (http:// apps.ecmwf.int/datasets/). The editor and two reviewers are acknowledged for providing valuable suggestions that substantially improved this manuscript.

\section{REFERENCES}

Bader, M. J., G. S. Forbes, J. R. Grant, R. B. E. Lilley, and A. J. Waters, 1995: Images in Weather Forecasting: A Practical Guide for Interpreting Satellite and Radar Imagery. Cambridge University Press, 523 pp. 
Berry, G., M. J. Reeder, and C. Jakob, 2011: A global climatology of atmospheric fronts. Geophys. Res. Lett., 38, L04809, doi:10.1029/2010GL046451.

Bjerknes, J., and H. Solberg, 1922: Life cycle of cyclones and the polar front theory of atmospheric circulation. Geofys. Publ., 3, $1-18$.

Browning, K. A., 1971: Radar measurements of air motion near fronts. Weather, 26, 293-304, doi:10.1002/j.1477-8696.1971. tb07416.x.

- 1986: Conceptual models of precipitation systems. Wea. Forecasting, 1, 23-41, doi:10.1175/1520-0434(1986)001<0023: CMOPS $>2.0 . \mathrm{CO} ; 2$.

- 1990: Organization of clouds and precipitation in extratropical cyclones. Extratropical Cyclones: The Erik Palmén Memorial Volume, C. Newton and E. O. Holopainen, Eds., American Meteorological Society, 129-154.

Carroll, E. B., 2003: Thermal advection, vorticity advection and potential vorticity advection in extra-tropical, synoptic-scale development. Meteor. Appl., 10, 281-292, doi:10.1017/ S1350482703003086.

Catto, J. L., and S. Pfahl, 2013: The importance of fronts for extreme precipitation. J. Geophys. Res. Atmos., 118, $10791-$ 10 801, doi:10.1002/jgrd.50852.

— L. C. Shaffrey, and K. I. Hodges, 2010: Can climate models capture the structure of extratropical cyclones? J. Climate, 23, 1621-1635, doi:10.1175/2009JCLI3318.1.

— C. Jakob, G. Berry, and N. Nicholls, 2012: Relating global precipitation to atmospheric fronts. Geophys. Res. Lett., 39, L10805, doi:10.1029/2012GL051736.

,,-- and N. Nicholls, 2013: A global evaluation of fronts and precipitation in the ACCESS model. Aust. Meteor. Ocean J., 63, 191-203.

— N. Nicholls, C. Jakob, and K. L. Shelton, 2014: Atmospheric fronts in current and future climates. Geophys. Res. Lett., 41, 7642-7650, doi:10.1002/2014GL061943.

Chang, E. K. M., Y. J. Guo, X. M. Xia, and M. H. Zheng, 2013: Storm-track activity in IPCC AR4/CMIP3 model simulations. J. Climate, 26, 246-260, doi:10.1175/JCLI-D-11-00707.1.

Dacre, H. F., P. A. Clark, O. Martinez-Alvarado, M. A. Stringer, and D. A. Lavers, 2015: How do atmospheric rivers form? Bull. Amer. Meteor. Soc., 96, 1243-1255, doi:10.1175/ BAMS-D-14-00031.1.

Dee, D. P., and Coauthors, 2011: The ERA-Interim reanalysis: Configuration and performance of the data assimilation system. Quart. J. Roy. Meteor. Soc., 137, 553-597, doi:10.1002/ qj.828.

Eckhardt, S., A. Stohl, H. Wernli, P. James, C. Forster, and N. Spichtinger, 2004: A 15-year climatology of warm conveyor belts. J. Climate, 17, 218-237, doi:10.1175/ 1520-0442(2004)017<0218:AYCOWC>2.0.CO;2.

Green, J. S. A., F. H. Ludlam, and J. F. R. McIlveen, 1966: Isentropic relative-flow analysis and the parcel theory. Quart. J. Roy. Meteor. Soc., 92, 210-219, doi:10.1002/qj.49709239204.

Harrold, T. W., 1973: Mechanisms influencing the distribution of precipitation within baroclinic disturbances. Quart. J. Roy. Meteor. Soc., 99, 232-251, doi:10.1002/qj.49709942003.

Hawcroft, M. K., L. C. Shaffrey, K. I. Hodges, and H. F. Dacre, 2012: How much Northern Hemisphere precipitation is associated with extratropical cyclones? Geophys. Res. Lett., 39, L24809, doi:10.1029/2012GL053866.

Hewson, T. D., 1998: Objective fronts. Meteor. Appl., 5, 37-65, doi:10.1017/S1350482798000553.
Hope, P., and Coauthors, 2014: A comparison of automated methods of front recognition for climate studies: A case study in southwest Western Australia. Mon. Wea. Rev., 142, 343363, doi:10.1175/MWR-D-12-00252.1.

Hoskins, B. J., and K. I. Hodges, 2002: New perspectives on the Northern Hemisphere winter storm tracks. J. Atmos. Sci., 59, 1041-1061, doi:10.1175/1520-0469(2002)059<1041: NPOTNH $>2.0 . \mathrm{CO} ; 2$.

—_, and - 2005: A new perspective on Southern Hemisphere storm tracks. J. Climate, 18, 4108-4129, doi:10.1175/ JCLI3570.1.

Joyce, R. J., J. E. Janowiak, P. A. Arkin, and P. Xie, 2004: CMORPH: A method that produces global precipitation estimates from passive microwave and infrared data at high spatial and temporal resolution. J. Hydrometeor., 5, 487-503, doi:10.1175/1525-7541(2004)005<0487:CAMTPG >2.0.CO;2.

Keyser, D., M. J. Reeder, and R. J. Reed, 1988: A generalization of Petterssen's frontogenesis function and its relation to the forcing of vertical motion. Mon. Wea. Rev., 116, 762-781, doi:10.1175/1520-0493(1988)116<0762:AGOPFF>2.0.CO;2.

Lavers, D. A., and G. Villarini, 2013: The nexus between atmospheric rivers and extreme precipitation across Europe. Geophys. Res. Lett., 40, 3259-3264, doi:10.1002/grl.50636.

Madonna, E., H. Wernli, H. Joos, and O. Martius, 2014: Warm conveyor belts in the ERA-Interim dataset (1979-2010). Part I: Climatology and potential vorticity evolution. J. Climate, 27, 3-26, doi:10.1175/JCLI-D-12-00720.1.

Ndarana, T., and D. W. Waugh, 2010: The link between cut-off lows and Rossby wave breaking in the Southern Hemisphere. Quart. J. Roy. Meteor. Soc., 136, 869-885, doi:10.1002/qi.627.

Nieto, R., and Coauthors, 2005: Climatological features of cutoff low systems in the Northern Hemisphere. J. Climate, 18, 30853103, doi:10.1175/JCLI3386.1.

Papritz, L., S. Pfahl, I. Rudeva, I. Simmonds, H. Sodemann, and H. Wernli, 2014: The role of extratropical cyclones and fronts for Southern Ocean freshwater fluxes. J. Climate, 27, 62056224, doi:10.1175/JCLI-D-13-00409.1.

Pfahl, S., and H. Wernli, 2012: Quantifying the relevance of cyclones for precipitation extremes. J. Climate, 25, 6770-6780, doi:10.1175/JCLI-D-11-00705.1.

_ E. Madonna, M. Boettcher, H. Joos, and H. Wernli, 2014: Warm conveyor belts in the ERA-Interim dataset (19792010). Part II: Moisture origin and relevance for precipitation. J. Climate, 27, doi:10.1175/JCLI-D-13-00223.1.

Pitt, M., 2008: The Pitt review: Learning lessons from the 2007 floods. Environment Agency Final Rep., 505 pp.

Renard, R. J., and L. C. Clarke, 1965: Experiments in numerical objective frontal analysis. Mon. Wea. Rev., 93, 547-556, doi:10.1175/1520-0493(1965)093<0547:EINOFA > 2.3.CO;2.

Risbey, J. S., M. J. Pook, P. C. McIntosh, C. C. Ummenhofer, and G. Meyers, 2009: Characteristics and variability of synoptic features associated with cool season rainfall in southeastern Australia. Int. J. Climatol., 29, 1595-1613, doi:10.1002/joc.1775.

Rudeva, I., and S. K. Gulev, 2011: Composite analysis of North Atlantic extratropical cyclones in NCEP-NCAR reanalysis data. Mon. Wea. Rev., 139, 1419-1446, doi:10.1175/2010MWR3294.1.

_ , and I. Simmonds, 2015: Variability and trends of global atmospheric frontal activity and links with large-scale modes of variability. J. Climate, 28, 3311-3330, doi:10.1175/ JCLI-D-14-00458.1.

Sansom, H. W., 1951: A study of cold fronts over the British Isles. Quart. J. Roy. Meteor. Soc., 77, 96-120, doi:10.1002/qj.49707733111. 
Schemm, S., and H. Wernli, 2014: The linkage between the warm and cold conveyor belts in an idealized extratropical cyclone. J. Atmos. Sci., 71, 1443-1459, doi:10.1175/JAS-D-13-0177.1.

,-- , and L. Papritz, 2013: Warm conveyor belts in idealized moist baroclinic wave simulations. J. Atmos. Sci., 70, 627-652, doi:10.1175/JAS-D-12-0147.1.

- I. Rudeva, and I. Simmonds, 2015: Extratropical fronts in the lower troposphere-Global perspectives obtained from two automated methods. Quart. J. Roy. Meteor. Soc., 141, 16861698, doi:10.1002/qj.2471.

Seluchi, M. E., and J. A. Marengo, 2000: Tropical-midlatitude exchange of air masses during summer and winter in South America: Climatic aspects and examples of intense events. Int J. Climatol., 20, 1167-1190, doi:10.1002/1097-0088(200008)20: $10<1167:$ :AID-JOC526>3.0.CO;2-T.

Simmonds, I., K. Keay, and E.-P. Lim, 2003: Synoptic activity in the seas around Antarctica. Mon. Wea. Rev., 131, 272-288, doi:10.1175/1520-0493(2003)131<0272:SAITSA > 2.0.CO;2.

,-- , and J. A. T. Bye, 2012: Identification and climatology of Southern Hemisphere mobile fronts in a modern reanalysis. J. Climate, 25, 1945-1962, doi:10.1175/ JCLI-D-11-00100.1.

Sodemann, H., and A. Stohl, 2013: Moisture origin and meridional transport in atmospheric rivers and their association with multiple cyclones. Mon. Wea. Rev., 141, 2850-2868, doi:10.1175/MWR-D-12-00256.1.

Wernli, H., 1997: A Lagrangian-based analysis of extratropical cyclones. II: A detailed case-study. Quart. J. Roy. Meteor. Soc., 123, 1677-1706, doi:10.1002/qj.49712354211.

- and H. C. Davies, 1997: A Lagrangian-based analysis of extratropical cyclones. I: The method and some applications. Quart. J. Roy. Meteor. Soc., 123, 467-489, doi:10.1002/qj.49712353811.

- , and C. Schwierz, 2006: Surface cyclones in the ERA-40 dataset (1958-2001). Part I: Novel identification method and global climatology. J. Atmos. Sci., 63, 2486-2507, doi:10.1175/JAS3766.1.

Zappa, G., L. C. Shaffrey, K. I. Hodges, P. G. Sansom, and D. B. Stephenson, 2013: A multimodel assessment of future projections of North Atlantic and European extratropical cyclones in the CMIP5 climate models. J. Climate, 26, 5846-5862, doi:10.1175/JCLI-D-12-00573.1. 